\title{
A benchmark theoretical study of the electronic ground state and of the singlet-triplet split of benzene and linear acenes
}

\author{
B. Hajgató, ${ }^{1,2}$ D. Szieberth, ${ }^{3}$ P. Geerlings, ${ }^{2}$ F. De Proft, ${ }^{2}$ and M. S. Deleuze ${ }^{1, a)}$ \\ ${ }^{1}$ Research Group of Theoretical Chemistry and Molecular Modeling, Hasselt University, \\ Agoralaan Gebouw D, Diepenbeek B-3590, Belgium \\ ${ }^{2}$ Eenheid Algemene Chemie (ALGC), Member of the QCMM-Alliance Ghent-Brussels, Belgium, \\ Vrije Universiteit Brussel (VUB), Pleinlaan 2, Brussels B-1050, Belgium \\ ${ }^{3}$ Department of Inorganic and Analytical Chemistry, Faculty of Chemical Engineering, \\ Budapest University of Technology and Economics, Gellert tér 4, Budapest H-1111, Hungary
}

(Received 21 August 2009; accepted 10 November 2009; published online 14 December 2009)

A benchmark theoretical study of the electronic ground state and of the vertical and adiabatic singlet-triplet (ST) excitation energies of benzene $(n=1)$ and $n$-acenes $\left(\mathrm{C}_{4 n+2} \mathrm{H}_{2 n+4}\right)$ ranging from naphthalene $(n=2)$ to heptacene $(n=7)$ is presented, on the ground of single- and multireference calculations based on restricted or unrestricted zero-order wave functions. High-level and large scale treatments of electronic correlation in the ground state are found to be necessary for compensating giant but unphysical symmetry-breaking effects in unrestricted single-reference treatments. The composition of multiconfigurational wave functions, the topologies of natural orbitals in symmetry-unrestricted CASSCF calculations, the T1 diagnostics of coupled cluster theory, and further energy-based criteria demonstrate that all investigated systems exhibit a ${ }^{1} A_{g}$ singlet closed-shell electronic ground state. Singlet-triplet $\left(S_{0}-T_{1}\right)$ energy gaps can therefore be very accurately determined by applying the principles of a focal point analysis onto the results of a series of single-point and symmetry-restricted calculations employing correlation consistent cc-pVXZ basis sets $(X=D, T, Q, 5)$ and single-reference methods [HF, MP2, MP3, MP4SDQ, CCSD, $\operatorname{CCSD}(\mathrm{T})]$ of improving quality. According to our best estimates, which amount to a dual extrapolation of energy differences to the level of coupled cluster theory including single, double, and perturbative estimates of connected triple excitations $[\operatorname{CCSD}(\mathrm{T})]$ in the limit of an asymptotically complete basis set (cc-pV $\infty \mathrm{Z})$, the $\mathrm{S}_{0}-\mathrm{T}_{1}$ vertical excitation energies of benzene $(n=1)$ and $n$-acenes $(n=2-7)$ amount to $100.79,76.28,56.97,40.69,31.51,22.96$, and $18.16 \mathrm{kcal} / \mathrm{mol}$, respectively. Values of $87.02,62.87,46.22,32.23,24.19,16.79$, and $12.56 \mathrm{kcal} / \mathrm{mol}$ are correspondingly obtained at the $\operatorname{CCSD}(\mathrm{T}) / \mathrm{cc}-\mathrm{pV} \infty \mathrm{Z}$ level for the $\mathrm{S}_{0}-\mathrm{T}_{1}$ adiabatic excitation energies, upon including B3LYP/cc-PVTZ corrections for zero-point vibrational energies. In line with the absence of Peierls distortions, extrapolations of results indicate a vanishingly small $\mathrm{S}_{0}-\mathrm{T}_{1}$ energy gap of 0 to $\sim 4 \mathrm{kcal} / \mathrm{mol}(\sim 0.17 \mathrm{eV})$ in the limit of an infinitely large polyacene.

(C) 2009 American Institute of Physics. [doi:10.1063/1.3270190]

\section{INTRODUCTION}

Polycyclic aromatic hydrocarbons (PAHs) have long been the focus of both theoretical and experimental research. ${ }^{1}$ They occur in nature mostly in traces embedded in different materials and their origin can be natural or anthropogenic. The primary sources of anthropogenic PAHs are from the burning of different organic materials, especially crude oil derivatives. ${ }^{2}$ Many of these compounds are extremely hazardous environmental pollutants. ${ }^{3}$ PAHs have also been identified in various extraterrestrial environments; they are known to be ubiquitous in the interstellar medium ${ }^{4}$ and thought to be responsible for diffuse interstellar bands and unidentified emission bands in the mid-IR range. ${ }^{5}$ Large PAHs are also used for modeling glassy carbon materials ${ }^{6}$ and graphitic sheets, or graphenes.

\footnotetext{
${ }^{a)}$ Author to whom correspondence should be addressed. Electronic mail: michael.deleuze@uhasselt.be.
}

Among all known PAH compounds, polyacenes probably aroused the greatest fantasies since they were predicted to behave as one-dimensional organic conductors with a zero-band gap, and to be subject to an opening of the bang gap due to Peierls distorsions only if the electron-phonon coupling exceeds the elastic energy strain associated with dimerization of the unit cell in a stiff lattice. ${ }^{8,9}$ Naphthacene (also referred to as tetracene), pentacene, and derivative compounds have been used recently to prepare highly ordered conducting organic materials or thin films with particularly large charge carrier mobilities. ${ }^{10}$ In contrast with the prevailing view ${ }^{11}$ that large acenes have a closed-shell singlet or open-shell triplet electronic ground states, a few groups $^{12-16}$ recently conjectured that large acenes such as hexacene, heptacene, or octacene should rather be regarded as open-shell singlet biradical systems, as a result of the instability of unrestricted (UBLYP, UB3LYP, UPW91, UBPW91, etc.) wave functions, in conjunction with rather modest basis sets (STO-3G, 6-31G*, or cc-pVDZ). This in- 
stability was diagnosed ${ }^{12}$ from the fact that in these unrestricted calculations the two outermost singly occupied $\alpha$ and $\beta$ spin orbitals do not smoothly follow the $\mathrm{D}_{2 \mathrm{~h}}$ symmetry point group imposed by the nuclear frame, but rather reflect an overwhelmingly strong symmetry breaking of the electronic wave function, ${ }^{12}$ in the form of a localization of the two frontier electrons on opposite polyacetylenic strands. Polyradical antiferromagnetic singlet ground states subject to strong nondynamical electronic correlation and with one unpaired electron spin every five to six rings would eventually be found upon proceeding further to acenes longer than dodecacene. $^{13,14}$

These findings are most intriguing, considering that the ionization and electron attachment energies ${ }^{17,18}$ of hexacene could be recently recovered within (or very near to) chemical (1 $\mathrm{kcal} / \mathrm{mol}$ ) accuracy from an extrapolation of various single-reference symmetry-restricted calculations to the level of coupled cluster theory incorporating single, double, and perturbative triple excitations $[\mathrm{CCSD}(\mathrm{T})]$ in the limit of an asymptotically complete basis set (CBS), by virtue of the principles of a focal point analysis (FPA) exploiting the faster convergence of the highest-order correlation corrections toward this limit. ${ }^{19-24}$ In continuation to several studies on many-body quantum mechanical grounds by our group $^{17,18,25}$ of the electronic properties, ionization, and shake-up spectra of large PAHs employing the restricted Hartree-Fock (RHF) wave function as zero-order solution, a first purpose of the present contribution is to assess the extent of multireference effects in the electronic ground state of benzene $(n=1)$ and $n$-acenes $\left(\mathrm{C}_{4 n+2} \mathrm{H}_{2 n+4}\right)$ ranging from naphthalene $(n=2)$ up to heptacene $(n=7)$, and to determine whether this state corresponds to a singlet closed-shell or a singlet open-shell wave function. Popular quantum chemistry methods such as MP2/6-311G** have, strangely enough, predicted benzene, naphthalene, anthracene, and further prototypical aromatic compounds to be nonplanar, because of an insidious intramolecular basis set incompleteness error: ${ }^{26}$ a deficiency from which the better balanced Dunning's correlation consistent basis sets do not suffer. Similarly, and notwithstanding all experimental evidences or common sense, it will be shown that even benzene and the smallest acenes can be subject to an artifactual symmetry breaking ${ }^{27,28}$ of their electronic wave function, yielding in turn a substantial but unphysical energy lowering thereby into an open-shell singlet ground state, depending on the employed method and basis set.

Electronic instabilities are the consequence of the nonanalyticity of variational self consistent field (SCF) procedures in symmetry breaking situations, which makes these procedures inadequate for describing such situations. ${ }^{29}$ Selfconsistent field Hamiltonian operators are not necessarily dilation analytic upon symmetry lowering, because of a nonphysical "overcounting" and amplification of the effect of the symmetry breaking by virtue of the SCF procedure. When using unrestricted wave functions as zero-order solutions, one must then pay more tribute in the treatment of static and/or dynamic correlation at a post-SCF level in order to compensate for the unphysical starting point, and recover the correct symmetries ${ }^{30}$ in charge and spin densities. ${ }^{31}$ Symme- try restricted SCF calculations are thus most generally advocated for producing meaningful zero-order singlet wave functions, prior to proceeding beyond the SCF level. In the present contribution, we will therefore comparatively study the performance of post-SCF restricted and unrestricted approached in tracking down the energy difference between the lowest singlet closed-shell and so-called singlet open-shell states of benzene and acenes toward the full-CI/CBS limit, a limit at which this difference must identically vanish.

Once the true nature of the electronic ground state of acenes is (re)established, we pursue this study by chasing toward the same confines of nonrelativistic quantum mechanics the energy difference between the singlet ground state and the lowest triplet state, which defines the so called singlet-triplet gap. This is an important electronic property, especially in those areas where photoluminescent processes take place. For example, singlet-triplet gaps can be used to evaluate the strength of electron-electron correlation in luminescent conjugated polymers. ${ }^{32}$ The singlet-triplet energy gaps of benzene and linear acenes have been measured decades ago, from phosphorescence spectra, and are well summarized in a 1967 paper, ${ }^{33}$ or in books ${ }^{34}$ by Birks. Note that most $\mathrm{S}_{0}-\mathrm{T}_{1}$ transition energies of aromatic compounds were measured at various temperatures in glasslike solid crystals, or in solutions. To our knowledge, the sole exception pertains to a determination of the $S_{0}-T_{1}$ energy gap of anthracene from photoelectron detachment experiments on the anion. ${ }^{35}$

Slight variations in the ST gaps of benzene and acenes ranging from 100 to $200 \mathrm{~cm}^{-1}(0.29-0.57 \mathrm{kcal} / \mathrm{mol})$ were observed in different matrices. The discrepancies can be larger in the case of (symmetry forbidden) weak vibrational $0-0$ components, as was for instance the case with benzene. ${ }^{33}$ The greatest care is needed with experimental values obtained for hexacene, which can only be synthesized in a polymethylmethacrylate matrix, where it remains stable up to $12 \mathrm{~h}$ at most. ${ }^{36}$ Heptacene can also be synthesized in the same matrix (under an inert atmosphere), where it can be maintained only up to $4 \mathrm{~h} ;{ }^{37}$ no one has ever managed to measure the ST gap of this compound so far. Except for multireference MRMP2/cc-pVDZ, ${ }^{38}$ CASCI/cc-pVDZ or CASCI/STO-3G studies $^{13}$ on systems as large as naphthacene, hexacene, or dodecacene, respectively, most theoretical determinations of oligo- and polyacenes are the result of calculations employing empirical (Hückel) ${ }^{8}$ or semiempirical (Parr-Pariser-Pople) Hamiltonians, ${ }^{9,39}$ Density Functional Theory (DFT), ${ }^{12,14}$ or Time-Dependent DFT (TDDFT). ${ }^{40}$ In spite of the fast convergence of results toward the size of the basis set, the accuracy of DFT or TDDFT calculations of excited states will always necessarily be limited by the approximate nature of the employed exchange-correlation functionals. On the other hand, besides the complications pertaining to the instability of closed-shell wave functions in a one-determinantal depiction, the greatest care is needed with the basis set in post-SCF calculations on large conjugated systems, because the influence of the basis set on correlated energies is known to rather rapidly increase with increasing system size, ${ }^{17}$ due to the progressive closure of the fundamental gap. Correlation consistent and exceedingly large basis sets of, at least, quadruple zeta quality are most 
generally required to achieve chemical accuracies $(1 \mathrm{kcal} /$ mol). Large scale many-body calculations of the excitation energies of acenes in vacuum at $0 \mathrm{~K}$ are therefore most clearly needed, considering the importance of these compounds in physics and chemistry.

The FPAs that are presented in the sequel are comparable to similar strategies pursuing chemical $[1 \mathrm{kcal} / \mathrm{mol}]$ or even subchemical $[0.1 \mathrm{kcal} / \mathrm{mol}]$ accuracies in benchmark studies of conformational energy differences or torsional barriers ${ }^{19}$ the barrier to linearity in water ${ }^{20}$ reaction and activation energies, ${ }^{21}$ ionization energies, ${ }^{22}$ heats of formation, ${ }^{23}$ binding energies of $\pi$-complexes, ${ }^{24}$ etc., which also combine (perturbative) MPn and (iterative) CC treatments. FPAs exploit the idea of a dual extrapolation toward the highest attainable level in electron correlation [ideally, the full-CI (configuration interaction) limit], in the limit of an asymptotically CBS. As in our previous works on the ionization energies and electron affinities of benzene and $n$-acenes, we here aim at achieving chemical accuracies through a determination of ST-energy gaps of these compounds at the $\operatorname{CCSD}(\mathrm{T}) / \mathrm{CBS}$ level.

\section{METHODOLOGY AND COMPUTATIONS}

All computations that are presented in this work have been performed on geometries that were optimized by means of DFT (Ref. 41) along with the Becke three-parameter LeeYang-Parr (B3LYP) functional ${ }^{42}$ and the cc-pVTZ basis set. ${ }^{43}$ Harmonic vibrational energies and zero-point energies were computed at the same level. The main motivation for using DFT (B3LYP) at this stage is that for strongly conjugated hydrocarbon molecules the computed structures and vibrational frequencies are known to be very much comparable $^{44}$ to results obtained by means of CCSD(T) (Ref. 45) (coupled cluster ansatz including single and double electronic excitations and supplemented by a perturbative treatment of triple excitations). Notwithstanding its moderate computational cost, the DFT/B3LYP approach has also been retained for optimizing geometries in the benchmark W1 thermochemical protocol by Martin and de Oliveira ${ }^{46}$ for exceedingly accurate thermochemical calculations of atomization energies and heats of formation. In this particular case, B3LYP bond lengths are within $0.02 \AA$ of the values obtained by means of $\mathrm{x}$-ray crystallographic studies of benzene and acenes (see Ref. 38 for a detailed comparison of B3LYP data with experimental structures).

Complete active space self-consistent field theory ${ }^{47}$ (CAS-SCF) and second order multiconfigurational perturbation theory ${ }^{48}$ (CASPT2) have been employed in order to evaluate the extent of static correlation in the ground state. Use was made of the so called $g 2$ Fock matrix formulation correction ${ }^{49}$ to remove the systematic error related to differences in the number of closed shell (paired) electrons (i.e., doubly occupied orbitals) in the case of CASPT2 calculations. ${ }^{50}$ In these multiconfigurational calculations, all electrons (including the core levels) were correlated. The employed active space encompasses the whole $\pi$ band systems of naphthalene (10 electrons in 10 spin orbitals) and anthracene (14 electrons in 14 spin orbitals). For longer acenes, an active space consisting of 14 electrons in 14 spin orbitals was retained. This active space was constructed from $2,1,2$, and 2 orbitals belonging to the $\mathrm{a}_{\mathrm{u}}, \mathrm{b}_{1 \mathrm{~g}}, \mathrm{~b}_{2 \mathrm{~g}}$, and $\mathrm{b}_{3 \mathrm{u}}$ irreducible representations of the symmetry point group of naphthacene and hexacene, whereas 2,1,3, and 1 orbitals of $a_{u}, b_{1 g}, b_{2 g}$, and $b_{3 u}$ symmetry character where retained for pentacene and heptacene, respectively.

Single point energy calculations have been performed at the level of Hartree-Fock theory ${ }^{51}$ (HF), of Møller-Plesset theory ${ }^{52}$ truncated at second-order ${ }^{53}$ (MP2), third-order ${ }^{54}$ (MP3), and fourth-order with single, double, and quadruple terms $^{55}$ (SDQ-MP4), as well as at the CCSD and CCSD(T) levels of coupled cluster theory in conjunction with basis sets of improving quality, under the approximation of frozen core $\left(\mathrm{C}_{1 \mathrm{~s}}\right)$ electrons at all correlated levels. The basis sets that were used in this study comprise: cc-pVDZ, ${ }^{43}$ cc-pVTZ, cc-pVQZ, ${ }^{43}$ cc-pV5Z, ${ }^{43,56}$ aug-cc-pVDZ, ${ }^{43,57}$ aug-cc-pVTZ, ${ }^{43,59}$ and aug-cc-pVQZ. ${ }^{43,59}$ The largest employed basis sets (cc-pV5Z up to anthracene, and cc-pVQZ from naphthacene) incorporate 876, 1350, 1824, 1350, 1630, 1910, and 2190 atomic basis functions when $n=1-7$, respectively. For the sake of simplicity, the SDQ-MP4 approach will be from now on referred to as the MP4 level. These single-point calculations were run onto the B3LYP/cc-pVTZ geometries of the ground state and of the first triplet excited states, in order to evaluate vertical and "well to well" $\mathrm{S}_{0}-\mathrm{T}_{1}$ excitation energies. In the sequel, these will be referred to as $\mathrm{VE}_{\mathrm{S}-\mathrm{T}}$ and $\mathrm{WWE}_{\mathrm{S}-\mathrm{T}}$ energy gaps, respectively. Adiabatic excitation energies $\left(\mathrm{AE}_{\mathrm{S}-\mathrm{T}}\right.$ energy gaps) were obtained by adding to the latter values B3LYP/cc-pVTZ corrections for zeropoint vibrational energies. This study was supplemented by multireference averaged quadratic coupled cluster ${ }^{58}$ (MRAQCC) calculations on benzene, in order to accurately treat vertical electronic excitations to degenerate states.

Most calculations, comprising geometry optimizations, vibrational analyses, as well as the single-point MP2, MP3, and MP4 energy calculations have been carried out using the GAUSSIAN03 (Ref. 59) program package. All CCSD and CCSD(T) single-point energy calculations on closed- and open-shell systems as well as the MR-AQCC calculations on benzene have been performed using the MOLPRO2000.1 package of programs, ${ }^{60}$ whereas MOLCAS5.4 (Ref. 61) was used to run all CASSCF and CASPT2 calculations. At last, we resorted to the ACES II (MAB) (Ref. 62) and MRCC (Ref. 63) packages of programs in order to perform further coupledcluster calculations at the $\mathrm{CC} 2,{ }^{64} \mathrm{CC} 3,{ }^{65} \mathrm{CC} 4,{ }^{66} \mathrm{CCSDT},{ }^{67}$ $\operatorname{CCSDT}(\mathrm{Q}),{ }^{68,66} \operatorname{CCSDTQ},{ }^{69}$ and $\operatorname{CCSDTQ}(\mathrm{P})^{66}$ levels, and study thereby the outcome of symmetry breakings toward and close to the full-CI limit, in small to medium-size basis sets. The main purpose of the latter calculations is to demonstrate that the idea of a singlet open-shell wave function for the ground state is physically unsound.

Total HF energies have been extrapolated to the limit of an asymptotically CBS from results obtained using Dunning's correlation consistent basis sets (cc-pVXZ, aug-cc-pVXZ) of improving quality, using Feller's threepoint extrapolation formula, ${ }^{70}$ 


$$
\mathrm{E}(l)=\mathrm{E}_{\infty}+\mathrm{Ae}^{-B l}
$$

where the cardinal $l$ number is $2,3,4 \cdots$ when $\mathrm{X}$ $=\mathrm{D}, \mathrm{T}, \mathrm{Q}, \cdots$. Many methods and basis sets have been used in the analysis and nonstandard notations are needed for simplifying the discussion. The result of a three-point energy extrapolation according to Feller's protocol from data obtained using the aug-cc-pVDZ, aug-cc-pVTZ, and aug-ccpVQZ basis sets will be for instance referred to as a F-AQZ result. The obtained result will be referred to as a F-5Z energy difference, if in the extrapolation use is made of data obtained using cc-pVTZ, cc-pVQZ, and cc-pV5Z basis sets. Thus, in our notation, the last suffix characterizes the degree of splitting (cardinal number, $\mathrm{X}$ ) of the largest basis set that has been used in the extrapolation and an "A" label precedes if the basis set is augmented by diffuse functions.

Electron correlation energies are extrapolated separately using a three-point extension ${ }^{71}$ of Schwartz extrapolation formula $^{72}$

$$
\mathrm{E}(l)=\mathrm{E}_{\infty}+\frac{\mathrm{B}}{\left(l+\frac{1}{2}\right)^{4}}+\frac{\mathrm{C}}{\left(l+\frac{1}{2}\right)^{6}} .
$$

The total energy at a given level in correlation in the limit of an asymptotically CBS is thus obtained in the latter case by adding to the extrapolated HF energy, according to Feller's method, the value obtained at this level of theory for the electron correlation energy by means of Eq. (2). Further notations are introduced here for discriminating the results obtained through applications of Schwartz's extrapolation approach at various theoretical levels [MP2, MP3, MP4, CCSD, $\operatorname{CCSD}(\mathrm{T})]$ along with different series of basis sets. For example, energies referred to as $\mathrm{S}_{\mathrm{MP} 2}-\mathrm{AQZ}$ results will be obtained as the sum of the HF energy extrapolated at the $\mathrm{HF} /$ aug-cc-pVœZ (F-AQZ) level, and of the MP2 electron correlation energy extrapolated in the limit of the same asymptotically CBS, according to a three-point Schwartz extrapolation employing the MP2/aug-cc-pVDZ, MP2/aug-ccpVTZ, and MP2/aug-cc-pVQZ single point results.

In our preceding works on ionization energies ${ }^{17}$ and electron affinities, ${ }^{18}$ we had, for practical reasons (lack of computational resources), to restrict ourselves to evaluations at the B3LYP/cc-pVTZ or B3LYP/cc-pVœZ levels of adiabatic geometrical relaxation (GRXE) energies, defined as energy differences between the vertical and geometrically relaxed geometries for the final state. In the present study, we wish to compare such estimates with highly accurate $\mathrm{CCSD}(\mathrm{T}) / \mathrm{cc}-\mathrm{pV} \infty \mathrm{Z}$ values for relaxation energies. As in our work in Ref. 18, or in an highly accurate study of atomization energies, ${ }^{73}$ B3LYP/cc-pVXZ $(X=\{D, T, Q\})$ energies will be extrapolated to the limit of the asymptotically complete cc-pVœZ basis set, according to Feller's three-point extrapolation scheme [Eq. (1)]. The main rationale for this is that electronic energies obtained using both DFT and HF methods are known to exhibit exponential convergence properties with regard to the largest angular momentum characterizing the atomic functions in the basis set. ${ }^{74}$

Further extrapolations were performed toward the CCSD(T) level of theory in the limit of an asymptotically CBS, using the principles of a FPA. In such an approach, the faster convergence of the higher-order correlation corrections to the calculated energy differences is exploited in wellsuited extrapolations of results obtained using $\operatorname{CCSD}(\mathrm{T})$ theory. To be more specific, reliable estimations of $\operatorname{CCSD}(\mathrm{T})$ energy differences in the limit of an infinitely large basis set can for instance be made by adding almost converged highlevel correlation corrections, derived at the MP4 and $\operatorname{CCSD}(\mathrm{T})$ levels of theory with rather limited basis sets, to lower-level HF and MP2 results which can be obtained in conjunction with much larger basis sets, along with the Feller's and Schwartz's extrapolations toward the CBS limit.

The outcome of further basis set extensions in the FPA has been carefully studied, through matching different levels of theory at the confines of the current computational possibilities. Various combinations are proposed in order to evaluate at best the errors made by evaluating at the $\operatorname{CCSD}(\mathrm{T}) /$ CBS level the energies of the lowest triplet states relative to the closed-shell ground states, using four different protocols for the extrapolation to this limit,

$$
\begin{aligned}
\mathrm{FPA}_{-} \mathrm{QZ}= & \mathrm{S}_{\mathrm{MP} 2}-\mathrm{QZ}+\left(\mathrm{E}_{\mathrm{MP} 4 / \mathrm{cc}-\mathrm{pVTZ}}-\mathrm{E}_{\mathrm{MP} 2 / \mathrm{cc}-\mathrm{pVTZ}}\right) \\
+ & \left(\mathrm{E}_{\mathrm{CCSD}(\mathrm{T}) / \mathrm{cc}-\mathrm{pVDZ}}-\mathrm{E}_{\mathrm{MP} 4 / \mathrm{cc}-\mathrm{pVDZ}}\right) \\
\mathrm{FPA}_{-} \mathrm{AQZ}= & \mathrm{S}_{\mathrm{MP} 2}-\mathrm{AQZ}+\left(\mathrm{E}_{\mathrm{MP} 4 / \text { aug-cc-pVTZ }}\right. \\
& \left.-\mathrm{E}_{\mathrm{MP} 2 / \text { aug-cc-pVTZ }}\right) \\
& +\left(\mathrm{E}_{\mathrm{CCSD}(\mathrm{T}) / \text { aug-cc-pVDZ }}-\mathrm{E}_{\mathrm{MP} 4 / \text { aug-cc-pVDZ }}\right),
\end{aligned}
$$

$$
\begin{aligned}
\mathrm{FPA}_{-} 5 \mathrm{Z}= & \mathrm{S}_{\mathrm{MP} 2}-5 \mathrm{Z}+\left(\mathrm{E}_{\mathrm{MP} 4 / \mathrm{cc}-\mathrm{pVTZ}}-\mathrm{E}_{\mathrm{MP} 2 / \mathrm{cc}-\mathrm{pVTZ}}\right) \\
& +\left(\mathrm{E}_{\mathrm{CCSD}(\mathrm{T}) / \mathrm{cc}-\mathrm{pVDZ}}-\mathrm{E}_{\mathrm{MP} 4 / \mathrm{cc}-\mathrm{pVDZ}}\right) \\
\mathrm{FPA}_{-} 5 \mathrm{Z} 2= & \mathrm{S}_{\mathrm{MP} 2}-5 \mathrm{Z}+\left(\mathrm{E}_{\mathrm{MP} 4 / \mathrm{cc}-\mathrm{pVQZ}}-\mathrm{E}_{\mathrm{MP} 2 / \mathrm{cc}-\mathrm{pVQZ}}\right) \\
& +\left(\mathrm{E}_{\mathrm{CCSD}(\mathrm{T}) / \mathrm{cc}-\mathrm{pVTZ}}-\mathrm{E}_{\mathrm{MP} 4 / \mathrm{cc}-\mathrm{pVTZ}}\right) .
\end{aligned}
$$

According to these definitions, FPA_AQZ results [Eq. (4)] are comparable to $\operatorname{CCSD}(\mathrm{T}) /$ aug-cc-pV $\infty \mathrm{Z}$ estimates, whereas all other extrapolations are expected to converge to the $\operatorname{CCSD}(\mathrm{T}) / \mathrm{cc}-\mathrm{pV} \infty \mathrm{Z}$ value. In view of the size of the largest employed basis sets (cc-pV5Z) in the extrapolation, the FPA_5Z2 protocol [Eq. (6)] is expected to provide the most accurate results.

\section{RESULTS AND DISCUSSION}

\section{A. Multi-reference effects and electronic instabilities in the electronic ground state}

Preliminary investigations of the lowest electronic states of linear acenes up to heptacene using the CAS-SCF/ CASPT2 method in conjunction with the cc-pVDZ and ccpVTZ basis sets indicate that, for all systems, the ground state is the closed-shell ${ }^{1} A_{g}$ reference, followed by ${ }^{3} B_{1 u}$ and ${ }^{1} B_{1 u}$ wave functions as lowest triplet and singlet excited states. This finding is obviously in sharp contradiction with the conclusions by Hachman et al. ${ }^{13}$ regarding the strong multireference and biradical (open-shell) nature of the ${ }^{1} A_{g}$ electronic structure of systems larger than pentacene, an ob- 
TABLE I. T1 diagnostics at the CCSD/cc-pVDZ level of theory and decomposition (in percent) of the TAEs in terms of contributions from the HF wave function and perturbative triple (T) excitations (upon a comparison of $\mathrm{HF} / \mathrm{cc}-\mathrm{pV} \infty \mathrm{Z}$ (F-QZ) with CCSD(T)/cc-pV $\infty \mathrm{Z}$ (FPA_QZ) results for TAEs) (calculations based on the B3LYP/cc-pVTZ geometries for the singlet closed-shell ground state).

\begin{tabular}{lccc}
\hline \hline & T1 & $\begin{array}{c}\mathrm{TAE}(\mathrm{HF})^{\mathrm{a}} \\
(\%)\end{array}$ & $\begin{array}{c}\mathrm{TAE}[(\mathrm{T})]^{\mathrm{b}} \\
(\%)\end{array}$ \\
\hline Benzene & 0.0098 & 75.97 & 1.39 \\
Naphthalene & 0.0103 & 75.51 & 1.56 \\
Anthracene & 0.0106 & 75.22 & 1.66 \\
Naphthacene & 0.0109 & 75.02 & 1.73 \\
Pentacene & 0.0112 & 74.86 & 1.78 \\
Hexacene & 0.0114 & 74.74 & 1.82 \\
Heptacene & 0.0115 & 74.65 & 1.85 \\
\hline \hline
\end{tabular}

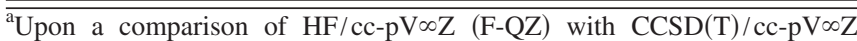
(FPA_QZ) results for TAEs.

${ }^{b}$ Upon a comparison of CCSD/cc-pVDZ, CCSD(T)/cc-pVDZ and $\mathrm{CCSD}(\mathrm{T}) / \mathrm{cc}-\mathrm{pV} \propto \mathrm{Z}$ (FPA_QZ) results for TAEs.

servation which requires a detailed analysis of electronic instabilities and multireference effects in the ground state of these compounds.

The square of the CI coefficients characterizing the two most important contributions to the CASSCF wave function of the $n$-acenes are far from being equal: these amount to 0.81 and $0.02,0.74$ and $0.02,0.74$ and $0.03,0.73$ and 0.04 , 0.68 and 0.06 , and 0.65 and 0.07 , when $n$ runs from 2 (naphthalene) to 7 (heptacene), respectively. All investigated CAS wave functions for the ground state are thus largely dominated by one configuration, indicating ${ }^{47}$ that all investigated systems are not subject to particularly strong nondynamical (static) correlation (arising from near-degeneracies among electronic configurations), but are rather dominated by dynamical correlation (arising from the Coulomb repulsion). In line with the composition of the CASSCF wave function, the $\mathrm{T} 1$ diagnostics ${ }^{75}$ of coupled cluster theory $(<0.012)$ indicates that all investigated compounds are merely of single reference nature (Table I).

A comparison of MP2 and CASPT2 estimates for the ST energy gap indirectly confirms the limited extent of multiref- erence effects in all investigated systems. For instance, the ST energy gaps of naphthalene and heptacene amount to 91.18 and $40.51 \mathrm{kcal} / \mathrm{mol}$ at the MP2/cc-pVDZ level, and to 71.10 and $16.39 \mathrm{kcal} / \mathrm{mol}$ at the CASPT2/cc-pVDZ level. Differences between these MP2/cc-pVDZ and CASPT2/ccpVDZ values are almost the same, being equal to 20.08 and $24.12 \mathrm{kcal} / \mathrm{mol}$, respectively. Although they seem highly impressive at first glance, these energy differences as such should not be ascribed solely to multireference effects, as CASPT2 reduces to MP2 when reducing the active space to zero orbital, but becomes equivalent to a full-CI treatment if the selected active space matches the whole orbital basis set. Therefore, differences between MP2 and CASPT2 results are active-space dependent and measure indirectly the contributions of higher-orders correlation terms. Since a large active space was employed in these multiconfigurational calculations, it is to be expected that single-reference MP2 and CASPT2 calculations based on a $\operatorname{CASSCF}(14,14)$ wave function give substantially different results, even if the reference wave function describes a closed-shell system. Naphthalene is most commonly known as a singlet closed-shell system, which can be correctly treated by single-reference theories. The discrepancy between the MP2/cc-pVDZ and CASPT2/cc-pVDZ values for the ST gap of heptacene being only marginally larger, by $4 \mathrm{kcal} / \mathrm{mol}$, there is thus definitely no indication at all in the CASPT2 results that heptacene would be subject to particularly strong multireference effects.

Computations of atomization energies represent the most stringent tests of the quality of many-body theories. The percentages of the total atomization energy (TAE) accounted for at the Hartree-Fock level, \%TAE(SCF), and by parenthetical connected triple excitations, \%TAE[(T)], are known to be reliable energy-based diagnostics for assessing the extent of nondynamical (i.e., multireference) correlation effects. ${ }^{76}$ For instance, $\% \mathrm{TAE}(\mathrm{SCF}) \geq 67 \%$ and/or $\% \mathrm{TAE}[(\mathrm{T})]<2 \%$ indicate systems that are dominated by dynamical correlation. Applying the above criteria to benzene and oligoacenes up to heptacene (Table I) further confirms that all these compounds exhibit very mild nondynamical correlation effects; $75 \%-$

TABLE II. Convergence toward the full-CI limit of the energies of benzene and naphthalene at improving levels of coupled cluster theory in conjunction with the STO-3G basis set, using restricted (RHF) closed-shell and unrestricted (UHF) "open-shell" singlet reference wave functions [calculations are based on B3LYP/cc-pVTZ geometries; all results are in hartree $(1$ a.u. $=27.2114 \mathrm{eV}=627.51 \mathrm{kcal} / \mathrm{mol})]$.

\begin{tabular}{|c|c|c|c|c|c|c|}
\hline & \multicolumn{3}{|c|}{ Benzene } & \multicolumn{3}{|c|}{ Naphthalene } \\
\hline & RHF & UHF & $\Delta \mathrm{E}(\mathrm{U}-\mathrm{R})$ & RHF & UHF & $\Delta \mathrm{E}(\mathrm{U}-\mathrm{R})$ \\
\hline $\mathrm{HF}$ & -227.89124 & -227.91019 & -0.01894 & -378.68485 & -378.73084 & -0.04599 \\
\hline $\mathrm{CC} 2$ & -228.23759 & -228.20940 & 0.02819 & -379.26420 & -379.21356 & 0.05064 \\
\hline $\mathrm{CC} 3$ & -228.31863 & -228.31436 & 0.00427 & -379.38882 & -379.37869 & 0.01013 \\
\hline $\mathrm{CC} 4$ & -228.32004 & -228.32011 & -0.00006 & -379.39173 & -379.39106 & 0.00067 \\
\hline CCSD & -228.31055 & -228.30158 & 0.00897 & -379.37270 & -379.35514 & 0.01756 \\
\hline CCSDT & -228.31949 & -228.31860 & 0.00089 & -379.39037 & -379.38674 & 0.00363 \\
\hline CCSDTQ & -228.32002 & -228.32000 & 0.00002 & $\ldots$ & $\ldots$ & $\ldots$ \\
\hline $\operatorname{CCSD}(\mathrm{T})$ & -228.31872 & -228.31271 & 0.00601 & -379.38897 & -379.37443 & 0.01454 \\
\hline $\operatorname{CCSDT}(\mathrm{Q})$ & -228.32004 & -228.32031 & -0.00027 & -379.39175 & -379.39047 & 0.00127 \\
\hline $\operatorname{CCSDTQ}(\mathrm{P})$ & -228.32004 & -228.32003 & 0.00001 & $\ldots$ & $\ldots$ & $\ldots$ \\
\hline
\end{tabular}


TABLE III. Evolution of the energies of pentacene with improving single-reference treatments of electron correlation in conjunction with various basis set, using closed-shell (RHF) and "open-shell" (UHF) singlet reference wave functions (WF) and B3LYP/cc-pVTZ geometries. Absolute energies are in hartree (1 a.u. $=27.2114 \mathrm{eV}=627.51 \mathrm{kcal} / \mathrm{mol})$, energy differences $(\Delta \mathrm{E})$ are in $\mathrm{kcal} / \mathrm{mol}$.

\begin{tabular}{|c|c|c|c|c|c|c|c|c|c|}
\hline $\begin{array}{l}\text { WF } \\
\text { Basis }\end{array}$ & $\begin{array}{c}\text { RHF } \\
\text { STO-3G }\end{array}$ & $\begin{array}{c}\text { UHF } \\
\text { STO-3G }\end{array}$ & $\begin{array}{c}\Delta \mathrm{E}(\mathrm{U}-\mathrm{R}) \\
\mathrm{STO}-3 \mathrm{G}\end{array}$ & $\begin{array}{l}\text { RHF } \\
6-31 G\end{array}$ & $\begin{array}{c}\text { UHF } \\
6-31 G\end{array}$ & $\begin{array}{c}\Delta \mathrm{E}(\mathrm{U}-\mathrm{R}) \\
6-31 \mathrm{G}\end{array}$ & $\begin{array}{c}\text { RHF } \\
\text { cc-pVDZ }\end{array}$ & $\begin{array}{c}\text { UHF } \\
\text { cc-pVDZ }\end{array}$ & $\begin{array}{c}\Delta \mathrm{E}(\mathrm{U}-\mathrm{R}) \\
\mathrm{cc}-\mathrm{pVDZ}\end{array}$ \\
\hline $\mathrm{HF}$ & -831.02371 & -831.19083 & -104.87 & -840.97882 & -841.06728 & -55.51 & -841.33543 & -841.41236 & -48.27 \\
\hline MP2 & -832.31168 & -832.14321 & 105.72 & -842.88174 & -842.73416 & 92.61 & -844.17683 & -844.01959 & 98.67 \\
\hline MP3 & -832.46295 & -832.31026 & 95.82 & -842.93747 & -842.84411 & 58.58 & -844.23927 & -844.15304 & 54.11 \\
\hline MP4SDQ & -832.49739 & -832.37704 & 75.52 & -842.97531 & -842.90254 & 45.67 & -844.24883 & -844.19138 & 36.05 \\
\hline CCSD & -832.53171 & -832.49903 & 20.51 & -842.98843 & -842.97238 & 10.07 & -844.25242 & -844.23972 & 7.97 \\
\hline $\operatorname{CCSD}(\mathrm{T})$ & -832.57627 & -832.53801 & 24.01 & -842.27021 & -842.28316 & 15.47 & $\ldots$ & $\ldots$ & $\ldots$ \\
\hline
\end{tabular}

$76 \%$ of the atomization energy is accounted for at the Hartree-Fock level and $1.4 \%-1.9 \%$ by the (T) triples. Note that in systems that are dominated by dynamical correlation, as is the case here, $\operatorname{CCSD}(\mathrm{T})$ is known to be generally very close to the full CI limit (within chemical accuracy), as the higher-order (nonperturbative) triple excitations, $\hat{\mathrm{T}}_{3}-(\mathrm{T})$, and the connected quadruple excitations, $\hat{\mathrm{T}}_{4}$, tend to largely cancel one another. ${ }^{76-78}$ Therefore, single-reference electron correlation methods such as MP2, MP3, MP4, CCSD, or $\operatorname{CCSD}(\mathrm{T})$ represent the most reasonable and most efficient path $^{28}$ toward the full-CI limit in a given basis set.

There is a consensus in the literature about the fact that linear acenes possess $D_{2 h}$ symmetry. ${ }^{13-15}$ In the work by Bendikov et al., ${ }^{12}$ in spite of marginal deviations of the molecular structure from the $\mathrm{D}_{2 \mathrm{~h}}$ symmetry point group, by $10^{-5}$ Angstroms or less, it was not possible to associate an electronic state with a correct symmetry label to the so called open shell singlet biradical states, because of exceedingly strong symmetry breakings in the associated unrestricted wave functions. Although all $\alpha$ and $\beta$ spin orbitals depart to varying extent from the $\mathrm{D}_{2 \mathrm{~h}}$ symmetry point group, our optimizations of the geometry of acenes in an "open-shell" singlet state at the UB3LYP/cc-pVTZ level and subsequent frequency calculations show that a molecular structure with a $\mathrm{D}_{2 \mathrm{~h}}$ symmetry point group corresponds to a true energy minimum for the ground state. Geometry optimizations and frequency calculations at the same level indicate that in their first triplet excited states, acenes exhibit also a $D_{2 h}$ symmetry point group. We shall now demonstrate that both the symmetry breaking of SCF orbitals in this point group and the as- sociated energy lowering in the ground state are artifacts resulting from an incomplete treatment of electronic correlation.

At the HF/STO-3G level, the open-shell singlet state of benzene or naphthalene lies at 11.9 or $28.9 \mathrm{kcal} / \mathrm{mol}$ below the expected closed-shell ground state, respectively (Table II). It is immediately apparent from this table that these energy differences reverse in favor of the closed-shell depiction at post-SCF levels and ultimately vanish when moving toward the full-CI limit. Thus, results obtained by means of treatments of electronic correlation of improving quality on both the symmetry broken singlet "open-shell" unrestricted Hartree-Fock (UHF) and the closed-shell RHF reference wave functions demonstrate that these states converge to the same energy limit, as expected, ${ }^{29}$ although RHF-based manybody calculations converge obviously faster to the FCI solution.

Similarly, at the HF/cc-pVDZ level, the symmetrybroken open-shell singlet states of pentacene, hexacene, and heptacene are located at 48.3, 65.2, and $84.9 \mathrm{kcal} / \mathrm{mol}$, respectively, below the closed-shell reference (Tables III-V). Again, these differences correspondingly reverse to 98.7, 115.0 , and $126.1 \mathrm{kcal} / \mathrm{mol}$ in favor of the closed-shell wave function at the MP2 level, and tend to vanish when proceeding further toward higher orders in correlation. For instance, the energy difference between the singlet open-shell and closed-shell ground states of pentacene reduces to $8.00 \mathrm{kcal} /$ mol only, when reaching the CCSD level (Table IV). The fact that at all post-SCF levels the singlet open-shell wave function is found to be unstable against the pairing of the two

TABLE IV. Evolution of the energies of hexacene with improving single-reference treatments of electron correlation in conjunction with the cc-pVDZ basis set, using closed-shell (CS) or "open-shell" (OS) singlet reference wave functions, as well as closed-shell (CS) singlet, "open-shell" (OS) singlet and triplet B3LYP/cc-pVTZ geometries B3LYP/cc-pVTZ geometries. Absolute energies are in hartree $(1$ a.u. $=27.2114 \mathrm{eV}=627.51 \mathrm{kcal} / \mathrm{mol})$ and energy differences are in $\mathrm{kcal} / \mathrm{mol}$.

\begin{tabular}{lcccccc}
\hline \hline $\begin{array}{l}\text { Geometry } \\
\text { State }\end{array}$ & $\begin{array}{l}\text { CS singlet } \\
\text { CS singlet }\end{array}$ & $\begin{array}{l}\text { CS singlet } \\
\text { OS triplet }\end{array}$ & $\begin{array}{c}\text { OS singlet } \\
\text { CS singlet }\end{array}$ & $\begin{array}{c}\text { OS singlet } \\
\text { OS singlet }\end{array}$ & $\begin{array}{c}\text { OS singlet } \\
\text { OS triplet }\end{array}$ & $\begin{array}{c}\text { OS triplet } \\
\text { OS triplet }\end{array}$ \\
\hline HF & -993.98137 & -993.98109 & -993.98119 & -994.08528 & -993.98158 & -993.99718 \\
MP2 & -997.34127 & -997.27630 & -997.34144 & -997.15820 & -997.27659 & -997.27852 \\
MP3 & -997.40924 & -997.36189 & -997.40926 & -997.31381 & -997.36227 & -997.36968 \\
MP4SDQ & -997.41981 & -997.38152 & -997.41979 & -997.35897 & -997.38194 & -997.39124 \\
CCSD & -997.42422 & -997.38708 & -997.42422 & $\ldots$ & -997.38752 & -997.39789 \\
CCSD(T) & -997.60143 & -997.56393 & -997.60152 & $\ldots$ & -997.56435 & -997.57338 \\
\hline \hline
\end{tabular}


TABLE V. Evolution of the energies of heptacene with improving single-reference treatments of electron correlation in conjunction with the cc-pVDZ basis set, using closed-shell (CS) or "open-shell" (OS) singlet reference wave functions, on the ground of closed-shell (CS) singlet, "open-shell" (OS) singlet and triplet B3LYP/cc-pVTZ geometries. Absolute energies are in hartree $(1$ a.u. $=27.2114 \mathrm{eV}=627.51 \mathrm{kcal} / \mathrm{mol})$ and energy differences are in kcal $/ \mathrm{mol}$.

\begin{tabular}{lllcccc}
\hline \hline $\begin{array}{l}\text { Geometry } \\
\text { State }\end{array}$ & $\begin{array}{l}\text { CS singlet } \\
\text { CS singlet }\end{array}$ & $\begin{array}{l}\text { CS singlet } \\
\text { OS triplet }\end{array}$ & $\begin{array}{l}\text { OS singlet } \\
\text { CS singlet }\end{array}$ & $\begin{array}{c}\text { OS singlet } \\
\text { OS singlet }\end{array}$ & $\begin{array}{c}\text { OS singlet } \\
\text { OS triplet }\end{array}$ & $\begin{array}{c}\text { OS triplet } \\
\text { OS triplet }\end{array}$ \\
\hline HF & -1146.62652 & -1146.64037 & -1146.62126 & -1146.76184 & -1146.64832 & -1146.65583 \\
MP2 & -1150.50558 & -1150.44103 & -1150.50767 & -1150.29925 & -1150.44301 & -1150.44166 \\
MP3 & -1150.57876 & -1150.53657 & -1150.57716 & -1150.47712 & -1150.54086 & -1150.54305 \\
MP4SDQ & -1150.59018 & -1150.55974 & -1150.58758 & -1150.52915 & -1150.56498 & -1150.56821 \\
CCSD & -1150.59548 & -1150.56728 & -1150.59345 & $\cdots$ & -1150.57326 & -1150.57715 \\
CCSD(T) & -1150.80209 & -1150.77204 & -1150.80186 & $\cdots$ & -1150.77768 & -1150.78051 \\
\hline
\end{tabular}

frontier electrons demonstrates once more that a closed-shell depiction for the electronic ground state prevails.

Interestingly, when considering DFT methods, stability tests indicate that the onset for a transition from a closedshell to an open-shell singlet ground state tends to shift toward larger acenes, upon decreasing the ratio of HF exchange in the employed exchange-correlation functional (Table VI). It would therefore certainly be worth studying in more detail the influence of nonlocal electronic exchange onto the nonanalyticity of variational SCF procedures, and on the extent therefore of the symmetry breakings ${ }^{29}$ in large conjugated systems.

CAS-SCF calculations are in principle more resilient to such complications than single-reference methods, a fact which is immediately apparent when comparing contour plots for the highest occupied natural orbital (HONO) and lowest occupied natural orbital (LUNO) obtained from CASSCF $(14,14) / c c-p V D Z$ calculations performed under the constraint of a $D_{2 h}$ symmetry point group [Fig. 1(a)] on heptacene with the results of $\operatorname{CASSCF}(12,12) / \mathrm{cc}-\mathrm{pVDZ}$ calculations with no symmetry constraint at all [Fig. 2(a)]. The comparison is extended further to contour plots for the canonical frontier orbitals [highest occupied molecular orbital (HOMO) and lowest unoccupied molecular orbital (LUMO)] of this compound, obtained using the restricted B3LYP/ccpVDZ and HF/cc-pVDZ [Figs. 1(b) and 1(c)] as well as the unrestricted UB3LYP/cc-pVDZ and UHF/cc-pVDZ [Figs. 2(b) and 2(c)] approaches. The extent of the symmetry breaking is obviously the most pronounced at the UHF level [Fig. 2(c)], whereas $D_{2 h}$ symmetry has been very effectively restored at the CASSCF $(12,12) / c c-p V D Z$ level [Fig. 2(a)]. In sharp contrast, contour plots are all essentially equivalent to the above CASCF/cc-pVDZ results when using restricted approaches (Fig. 1). This demonstrates further on topological grounds the relevance of RHF single determinants as meaningful zero-order singlet ground states, which must be clearly preferred over UHF wave functions in accurate treatments of dynamical correlation.

We also provide in Fig. 3 contour plots for the frontier orbitals obtained from symmetry-unrestricted $\mathrm{CAS}(N, N) /$ cc-pVDZ calculations on heptacene employing increasing active spaces $(N=2,4,6,8,10,12)$. Although these calculations were based on the symmetry-broken $\left(\mathrm{C}_{2 \mathrm{v}}\right)$ $\alpha$-part of the UHF wave function as input, they nicely enlighten the convergence of the natural orbitals of large acenes to extensively delocalized topologies, which very much resemble canonical RHF orbitals belonging to the $\mathrm{B}_{2 \mathrm{~g}}$ and $\mathrm{B}_{3 \mathrm{u}}$ irreducible representations of the $\mathrm{D}_{2 \mathrm{~h}}$ symmetry point group, in the limit of a complete active space. The corresponding occupation numbers for the HONO and LUNO are equal to $1.88,1.86,1.84,1.87,1.79$, and 1.78 , and to $0.12,0.13,0.16$,

TABLE VI. Closed-shell singlet and "open-shell” singlet cross-over points of various DFT functionals.

\begin{tabular}{|c|c|c|c|c|}
\hline Functional & $\begin{array}{c}\text { HF exchange } \\
(\%)\end{array}$ & Basis & Geometry & $\begin{array}{l}\text { First "open shell" } \\
\text { in the series }\end{array}$ \\
\hline $\mathrm{HF}$ & 100 & cc-pVDZ & RB3LYP/cc-pVTZ & Benzene \\
\hline MPW $1 K^{\mathrm{a}}$ & 42.80 & cc-pVDZ & RB3LYP/cc-pVTZ & Naphthacene \\
\hline B3LYP ${ }^{b}$ & 20 & $6-31 G^{*}$ & UB3LYP/6-31G* & Hexacene \\
\hline PW91 $1^{\mathrm{b}, \mathrm{c}}$ & 0 & $6-31 G^{*}$ & UPW91/6-31G* & Heptacene \\
\hline BPW91 & 0 & $6-31 G^{*}$ & UBPW91/6-31G* & Heptacene \\
\hline $\mathrm{TPSS}^{\mathrm{e}}$ & 0 & cc-pVDZ & RB3LYP/cc-pVTZ & Heptacene \\
\hline $\mathrm{BLYP}^{\mathrm{b}, \mathrm{f}}$ & 0 & $6-31 G^{*}$ & UBLYP/6-3G* & Octacene \\
\hline $\mathrm{PBE}^{\mathrm{g}}$ & 0 & cc-pVDZ & RB3LYP/cc-pVTZ & Octacene \\
\hline
\end{tabular}

\footnotetext{
${ }^{\mathrm{a}}$ Modified Perdew-Wang one-parameter for kinetics (Ref. 90).

${ }^{\mathrm{b}}$ From Ref. 12.

${ }^{c}$ Perdew-Wang 1991 functional (Ref. 91).

dBecke's 1988 exchange functional and Perdew-Wang 1991 correlation functional (Ref. 92).

${ }^{\mathrm{e}}$ Tao, Perdew, Staroverov, and Scuseria functional (Ref. 93).

'Becke's 1988 exchange functional along with the correlation functional of Lee, Yang, and Parr (Refs. 92 and 42).

${ }^{\mathrm{g}}$ Perdew, Burke, and Ernzerhof 1996 functional (Ref. 94).
} 
(a)

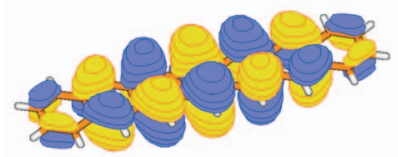

CAS $(14,14)$ HONO

(b)

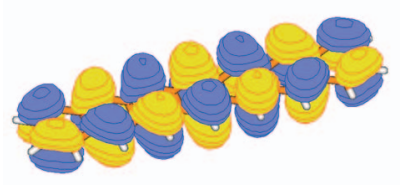

RB3 HOMO

(c)

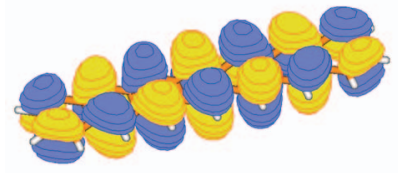

RHF HOMO

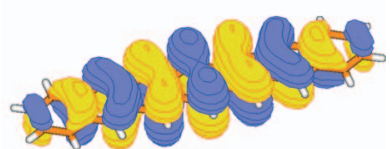

CAS $(14,14)$ LUNO

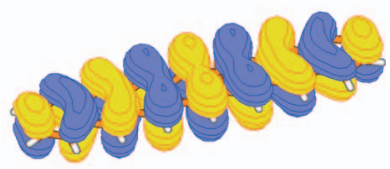

RB3 LUMO

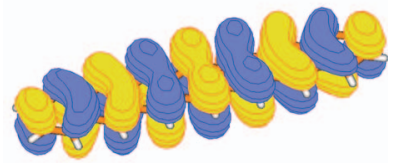

RHF LUMO

FIG. 1. Contour plots (Ref. 96) of the highest occupied molecular/natural orbitals and lowest unoccupied molecular/natural orbitals of heptacene. (a) CASCF $(14,14) / c c-p V T Z / / R B 3 L Y P / c c-p V T Z$, (b) RB3LYP/cc-pVTZ, and (c) RHF/cc-pVTZ [symmetry restricted $\left(\mathrm{D}_{2 \mathrm{~h}}\right)$ calculations upon the RB3LYP/cc-pVTZ geometry].

$0.13,0.21$, and 0.22 , respectively, which demonstrates further that a single-reference closed-shell depiction prevails.

At last, we wish to close this discussion on the electronic ground state of $n$-acenes by showing that the change in the electronic structure detected at the level of hexacene by Hachmann et al. in Ref. 13 from a barely visible variation in the scaling properties of estimates of the numbers of unpaired electrons derived from CASCI natural occupations should not be regarded as the sign of a major transition in the electronic structure toward a biradical or multiradical regime. It rather reflects the fact that, from this compound, inappropriate singlet open-shell UB3LYP/6-31G* ${ }^{*}$ geometries, ${ }^{12}$ resembling very closely the triplet geometries, were used; compared with the RB3LYP geometries, these UB3LYP geometries exhibit a reversal of bond length alternations (Fig. 4). Note also that, according to the estimates that were used in the analysis by Hachmann et al., ${ }^{13}$ even naphthalene would contain one to two unpaired electron spins, which is obviously in sharp contradiction with the most commonly accepted closed-shell depiction for the electronic ground state of this compound.

\section{B. Vertical singlet-triplet gaps}

The results of the FPAs of the vertical singlet-triplet $\left(\mathrm{VE}_{\mathrm{S}-\mathrm{T}}\right)$ gaps of benzene and acenes are given as the main entries in Tables VII-XIII. These results can be readily compared with the values correspondingly obtained for the "well-to-well" $\left(\mathrm{WWE}_{\mathrm{S}-\mathrm{T}}\right)$ excitation energies, which are provided in brackets. In these tables, the HF values for the singlet-triplet energies are reported as $\Delta \mathrm{HF}$ results. In the following rows, we provide the outcome of successive improvements in treating electronic correlation. More specifi-

(a)

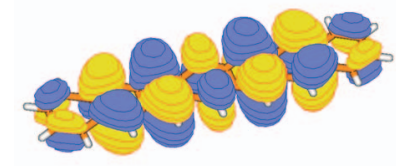

CAS $(12,12)$ HONO

(b)

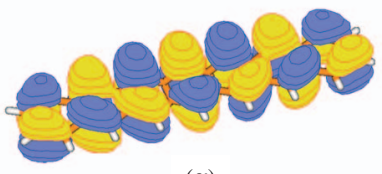

$(\alpha)$

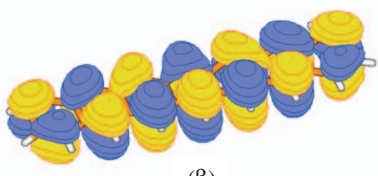

( $\beta)$

(c)

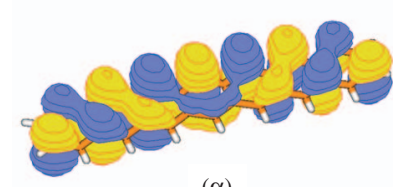

$(\alpha)$

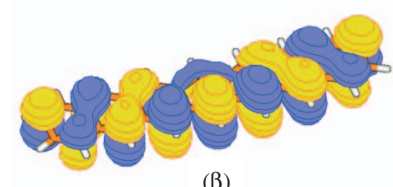

( $\beta)$

UHF HOMO

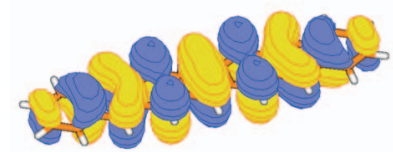

CAS(12,12) LUNO

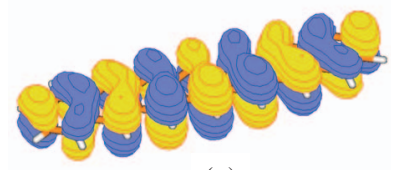

$(\alpha)$

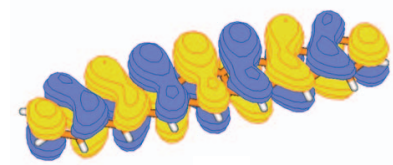

( $\beta)$

UB3 LUMO

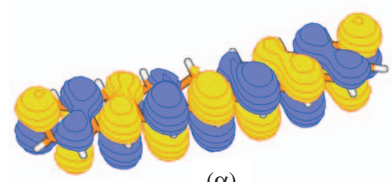

$(\alpha)$

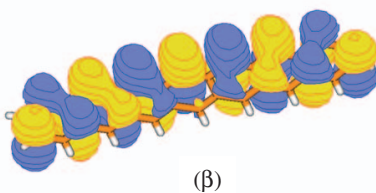

UHF LUMO
FIG. 2. Contour plots (Ref. 96) of the highest occupied molecular/natural orbitals and lowest unoccupied molecular/natural orbitals of heptacene. (a) CASCF(12,12)/cc-pVTZ, (b) UB3LYP/cc-pVTZ, and (c) UHF/cc-pVTZ results (symmetry unrestricted calculations upon the RB3LYP/cc-pVTZ geometry).

cally, values reported under the +MP2, +MP3, +MP4, $+\mathrm{CCSD}$, and $+\mathrm{CCSD}(\mathrm{T})$ entries correspond to the corrections obtained at the MP2, MP3, MP4, CCSD, and CCSD(T) levels, compared to the HF, MP2, MP3, MP4, and CCSD levels, respectively. Comparison is then made between $\triangle \mathrm{CCSD}(\mathrm{T}), \triangle \mathrm{CASSCF}$ and, in the case of benzene, $\triangle \mathrm{MR}-\mathrm{AQCC}$ results for singlet-triplet excitation energies. For the sake of clarity, we shall in this section concentrate on the vertical excitation energies and postpone the discussion of the $\mathrm{WWE}_{\mathrm{S}-\mathrm{T}}$ data to the next section.

Under $\mathrm{D}_{6 \mathrm{~h}}$ symmetry, the lowest vertical triplet excited state of benzene has two degenerate and partially filled orbitals, therefore, straightforward applications of onedeterminant methods like HF or DFT give rise to a symmetry breaking of the electronic wave function compared to the geometry of the nuclear frame. To correctly treat this electronically degenerate state within the right symmetry point group, one has to resort to multireference or multistate methods. The vertical singlet-triplet gap of benzene has thus been calculated according to MR-AQCC $(4,4)$ calculations based on a CAS-SCF $(4,4)$ wave function, thereby using the minimal size active/reference space at the CAS-SCF level, which 
(a)

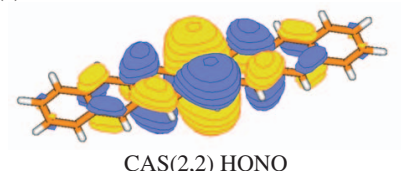

(b)

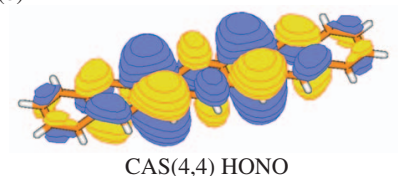

(c)

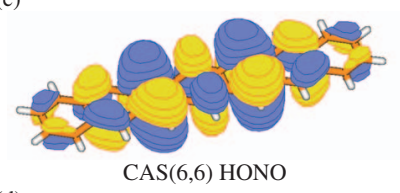

(d)

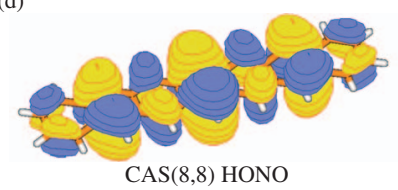

(e)

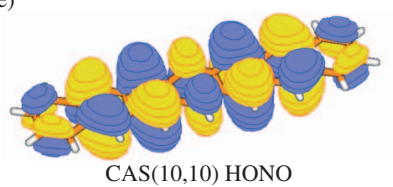

(f)

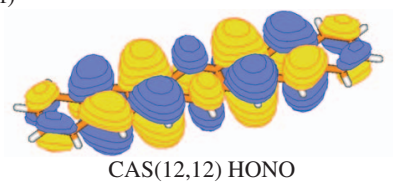

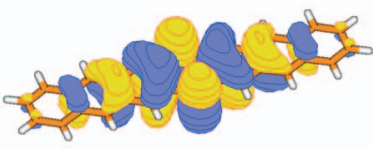

CAS(2,2) LUNO

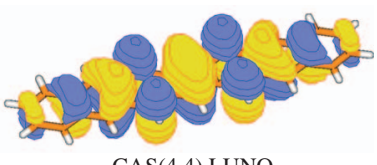

CAS $(4,4)$ LUNO
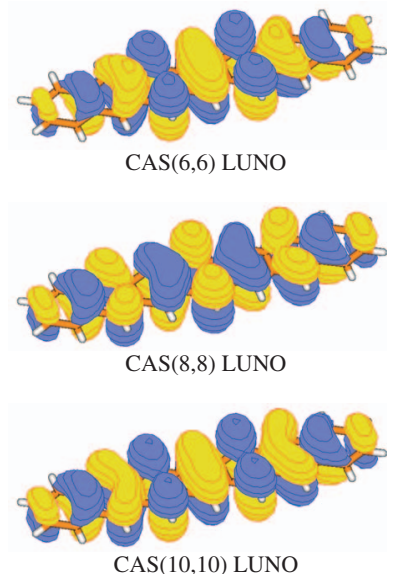

CAS $(10,10)$ LUNO

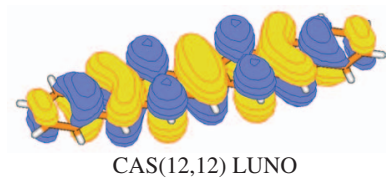

FIG. 3. Evolution of the highest occupied and lowest unoccupied natural orbitals of heptacene, according to symmetry unrestricted $\left(\mathrm{C}_{1}\right)$ $\operatorname{CASSCF}(N, N)$ / cc-pVTZ/ / RB3LYP/cc-pVTZ calculations: (a) $N=2$, (b) $N=4$, (c) $N=6$, (d) $N=8$, (e) $N=10$ ), and (f) $N=12$.

consists of four electrons distributed in four active orbitals, since both the HOMO and LUMO of benzene are doubly degenerate. All configurations produced in this CAS$\operatorname{SCF}(4,4)$ calculation were these used as reference states for the MR-AQCC calculations. Accounting for the symmetry breaking of the electron density in the triplet excited state results into a decrease in the vertical singlet-triplet energy gap by $3.57 \mathrm{kcal} / \mathrm{mol}$ (only) at the MR-AQCC $(4,4) /$ aug-ccpVQZ level of theory, a value which measures the extent of multireference effects in the triplet excited state.

The first conclusions that can be drawn from Tables VII-XIII are that the $\Delta \mathrm{HF}$ values converge rather rapidly to finite values with respect to an increase in the cardinal number, $l$, and, thereby, successive improvements of the quality of the basis set. Note that, due to the neglect of dynamical correlation, HF theory incorrectly predicts the triplet state to be the electronic ground state of hexacene (Table XII) and heptacene (Table XIII). Another striking trend that emerges from our results is that $+\mathrm{MP} 2$ corrections are systematically positive and largely dominate the vertical ST-gap of pentacene (Tables XI), hexacene (Table XII), and heptacene (Table XIII). On the contrary, higher-order (+MP3, + MP4, $\cdots$, etc.) perturbation corrections always yield a decrease in this gap. The extent of the successive +MP2,
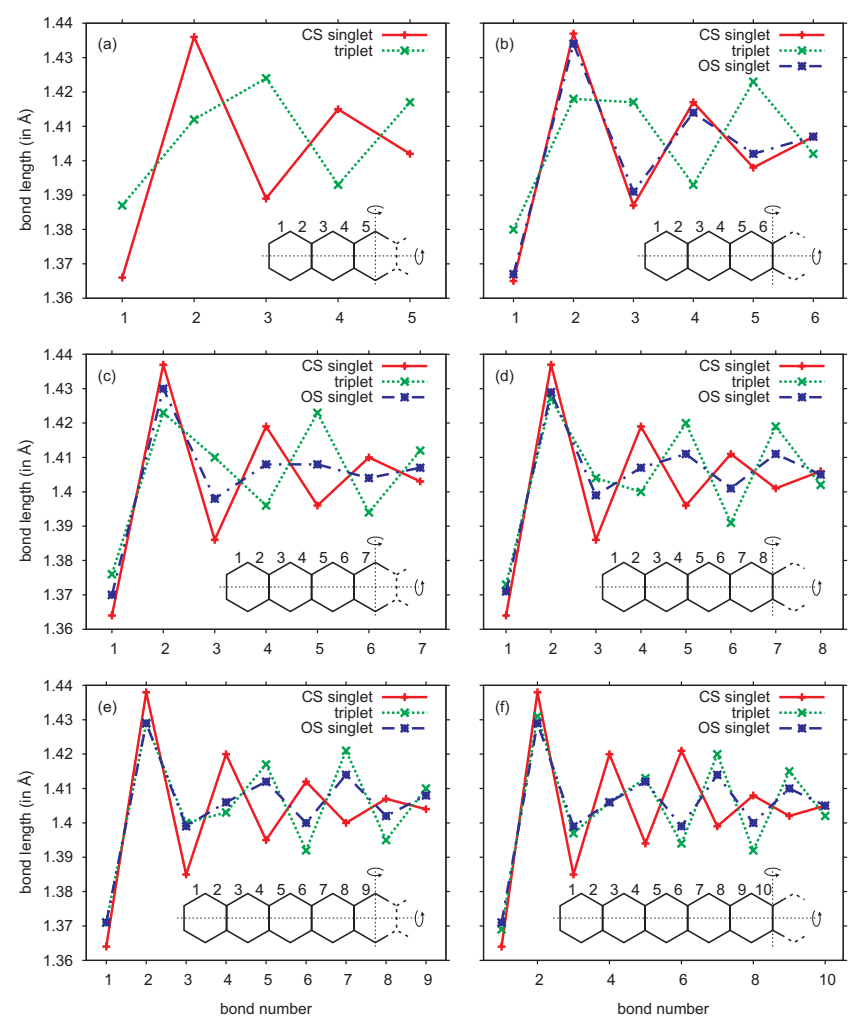

FIG. 4. Closed shell (RB3LYP/6-31G*), open shell singlet (UB3LYP/6-31G*), and triplet (UB3LYP/6-31G*) outer bond lengths of (a) pentacene, (b) hexacene, (c) heptacene, (d) octacene, (e) nonacene, and (f) decacene. Data taken from Ref. 12, employed in Ref. 13.

$+\mathrm{MP} 3$, and +MP4 corrections are first decreasing, and then increasing again (from around naphthacene) upon an increase in system size. In contrast, the total $[\operatorname{CCSD}(\mathrm{T})$ versus $\mathrm{HF}$ ] correlation corrections are increasing monotonically with system size. A similar trend was observed in a systematic study of the ionization energies of linear acenes. ${ }^{17}$ The $+\mathrm{CCSD}$ and $+\mathrm{CCSD}(\mathrm{T})$ correlation corrections are small and show overall an oscillatory convergence upon an increase in system size. Convergence upon improvements of the basis set is smooth at all levels in the treatment of electronic correlation, which enables quantitative extrapolations to the limit of an infinitively large basis set. For instance, results obtained for naphthalene using the cc-pVXZ $(X=D, T)$ basis sets demonstrate that the $+\operatorname{CCSD}[+\operatorname{CCSD}(\mathrm{T})]$ corrections to the MP4SDQ [CCSD] values for the ST gaps have converged below $1 \mathrm{kcal} / \mathrm{mol}$ with regard to the basis set when $\mathrm{X}=\mathrm{D}$. Basis set extrapolations employing triple-, quadruple-, and quintuple-zeta basis yield slight increases, of the order of one-fourth of a $\mathrm{kcal} / \mathrm{mol}$ only, of the singlet-triplet gaps obtained at the MP2 level, compared to extrapolations made using smaller basis sets. Our $\operatorname{CCSD}(\mathrm{T}) / \mathrm{cc}-\mathrm{pV} \infty \mathrm{Z}$ (FPA_5Z2) values $(56.97$ and $40.69 \mathrm{kcal} / \mathrm{mol})$ for the vertical ST-gap of anthracene $(n=3)$ and naphthacene $(n=4)$ are much larger than the MRMP2/cc-pVDZ values (46.12 and $34.82 \mathrm{kcal} / \mathrm{mol}$, respectively) reported by Kawashima et $a l .,{ }^{38}$ an observation which sheds light on rather serious shortcomings in the latter study with regards to the employed CASSCF geometries, as well as in the $\pi$-valence $(12,12)$ 
TABLE VII. FPA of the vertical singlet-triplet gaps of benzene (all energies and corrections are given in $\mathrm{kcal} / \mathrm{mol}$ ). The $\Delta$ values are the singlet-triplet energy gaps at a given level. The $+\mathrm{MP} 2,+\mathrm{MP} 3,+\mathrm{MP} 4,+\mathrm{CCSD}$, and $+\mathrm{CCSD}(\mathrm{T})$ entries correspond to the corrections obtained at the MP2, MP3, MP4, CCSD, and CCSD(T) levels, compared with the HF, MP2, MP3, MP4, and CCSD levels, respectively. "Well-to-well" $\mathrm{S}_{0}-\mathrm{T}_{1}$ excitation energies (WWE $\mathrm{S}_{\mathrm{S}}$ ) results are correspondingly given in parentheses.

\begin{tabular}{|c|c|c|c|c|c|c|c|c|c|c|}
\hline \multicolumn{11}{|c|}{ Benzene } \\
\hline No. basis & $\begin{array}{c}\text { cc-pVDZ } \\
114\end{array}$ & $\begin{array}{l}\text { cc-pVTZ } \\
264\end{array}$ & $\begin{array}{l}\text { cc-pVQZ } \\
510\end{array}$ & $\begin{array}{l}\text { cc-pV5Z } \\
876\end{array}$ & $\begin{array}{c}\text { aug-cc-pVDZ } \\
192\end{array}$ & $\begin{array}{c}\text { aug-cc-pVTZ } \\
414\end{array}$ & $\begin{array}{c}\text { aug-cc-pVQZ } \\
756\end{array}$ & F/S-QZ & F/S-AQZ & F/S-5Z \\
\hline$\Delta \mathrm{HF}$ & $\begin{array}{c}78.99 \\
(63.13)\end{array}$ & $\begin{array}{c}77.79 \\
(63.09)\end{array}$ & $\begin{array}{c}77.57 \\
(63.06)\end{array}$ & $\begin{array}{c}77.48 \\
(63.07)\end{array}$ & $\begin{array}{l}78.30 \\
(-)\end{array}$ & $\begin{array}{l}77.61 \\
(-)\end{array}$ & $\begin{array}{l}77.48 \\
(-)\end{array}$ & $\begin{array}{c}77.52^{\mathrm{a}} \\
(63.04)^{\mathrm{a}}\end{array}$ & $\begin{array}{l}77.47^{\mathrm{b}} \\
(-)\end{array}$ & $\begin{array}{l}77.44^{\mathrm{c}} \\
(63.08)^{\mathrm{c}}\end{array}$ \\
\hline$+\mathrm{MP} 2$ & $\begin{array}{c}46.84 \\
(47.77)\end{array}$ & $\begin{array}{c}48.08 \\
(50.40)\end{array}$ & $\begin{array}{c}48.51 \\
(51.29)\end{array}$ & $\begin{array}{c}48.62 \\
(51.52)\end{array}$ & $\begin{array}{l}46.86 \\
(-)\end{array}$ & $\begin{array}{l}47.83 \\
(-)\end{array}$ & $\begin{array}{l}48.39 \\
(-)\end{array}$ & $\begin{array}{c}48.62^{\mathrm{d}} \\
(51.51)^{\mathrm{d}}\end{array}$ & $\begin{array}{c}48.53^{\mathrm{e}} \\
(-)\end{array}$ & $\begin{array}{l}48.67^{\mathrm{f}} \\
(51.67)^{\mathrm{f}}\end{array}$ \\
\hline$+\mathrm{MP} 3$ & $\begin{array}{c}-12.60 \\
(-13.89)\end{array}$ & $\begin{array}{c}-14.17 \\
(-15.38)\end{array}$ & $\begin{array}{c}-14.65 \\
(-15.88)\end{array}$ & & $\begin{array}{c}-12.87 \\
(-)\end{array}$ & $\begin{array}{c}-14.25 \\
(-)\end{array}$ & $\begin{array}{c}-14.70 \\
(-)\end{array}$ & $\begin{array}{c}-14.85^{\mathrm{g}} \\
(-)\end{array}$ & $\begin{array}{c}-14.82^{\mathrm{h}} \\
(-)\end{array}$ & \\
\hline +MP4(SDQ) & $\begin{array}{c}-4.88 \\
(-4.72)\end{array}$ & $\begin{array}{c}-5.37 \\
(-5.23)\end{array}$ & $\begin{array}{c}-5.58 \\
(-5.46)\end{array}$ & & $\begin{array}{l}-5.51 \\
(-)\end{array}$ & $\begin{array}{l}-5.58 \\
(-)\end{array}$ & $\begin{array}{c}-5.66 \\
(-)\end{array}$ & $\begin{array}{c}-5.55^{\mathrm{i}} \\
(-)\end{array}$ & $\begin{array}{c}-5.68^{\mathrm{j}} \\
(-)\end{array}$ & \\
\hline$+\mathrm{CCSD}$ & $\begin{array}{l}-2.90 \\
(-2.79)\end{array}$ & $\begin{array}{l}-1.87 \\
(-1.83)\end{array}$ & $\begin{array}{l}-1.55 \\
(-)\end{array}$ & & $\begin{array}{l}-2.43 \\
(-)\end{array}$ & $\begin{array}{l}-1.67 \\
(-)\end{array}$ & $\begin{array}{c}-1.46 \\
(-)\end{array}$ & $\begin{array}{c}-1.47^{\mathrm{k}} \\
(-)\end{array}$ & $\begin{array}{c}-1.41^{1} \\
(-)\end{array}$ & \\
\hline$+\operatorname{CCSD}(\mathrm{T})$ & $\begin{array}{c}0.01 \\
(0.43)\end{array}$ & $\begin{array}{c}0.36 \\
(0.63)\end{array}$ & $\begin{array}{l}0.40 \\
(-)\end{array}$ & & $\begin{array}{l}0.16 \\
(-)\end{array}$ & $\begin{array}{l}0.38 \\
(-)\end{array}$ & $\begin{array}{l}0.40 \\
(-)\end{array}$ & $\begin{array}{l}0.41^{\mathrm{m}} \\
(-)\end{array}$ & $\begin{array}{l}0.42^{\mathrm{n}} \\
(-)\end{array}$ & \\
\hline$\Delta \operatorname{CCSD}(\mathrm{T})$ & $\begin{array}{l}105.45 \\
(89.93)\end{array}$ & $\begin{array}{l}104.82 \\
(91.67)\end{array}$ & $\begin{array}{c}104.70 \\
(-)\end{array}$ & & $\begin{array}{c}104.50 \\
(-)\end{array}$ & $\begin{array}{c}104.32 \\
(-)\end{array}$ & $\begin{array}{c}104.46 \\
(-)\end{array}$ & & & \\
\hline$\Delta \operatorname{CASSCF}(4,4)$ & 111.08 & 110.69 & 110.53 & & 110.48 & 110.45 & 110.42 & & & \\
\hline$\Delta \mathrm{MR}-\mathrm{AQCC}(4,4)$ & 100.59 & 100.50 & 100.61 & & 100.15 & 100.26 & 100.49 & & & \\
\hline $\begin{array}{l}{ }^{\mathrm{a}} \mathrm{F}-\mathrm{QZ} . \\
{ }^{\mathrm{b}} \mathrm{F}-\mathrm{AQZ} . \\
{ }^{\mathrm{c}} \mathrm{F}-5 \mathrm{Z} . \\
{ }^{\mathrm{d}} \mathrm{S}_{\mathrm{MP2}}-\mathrm{QZ} . \\
{ }^{\mathrm{e}} \mathrm{S}_{\mathrm{MP2}}-\mathrm{AQZ} . \\
{ }^{\mathrm{f}} \mathrm{S}_{\mathrm{MP}}-5 Z . \\
{ }^{\mathrm{g}} \mathrm{S}_{\mathrm{MP} 3}-\mathrm{QZ} .\end{array}$ & & & & & $\begin{array}{l}{ }^{\mathrm{h}} \mathrm{S}_{\mathrm{MP3}} \\
{ }^{\mathrm{i}} \mathrm{S}_{\mathrm{MP4}} \\
{ }^{\mathrm{j}} \mathrm{S}_{\mathrm{MP4}} \\
{ }^{\mathrm{k}} \mathrm{S}_{\mathrm{CCS}} \\
{ }^{\mathrm{l}} \mathrm{S}_{\mathrm{CCS}} \\
{ }^{\mathrm{m}} \mathrm{S}_{\mathrm{CCS}} \\
{ }^{\mathrm{n}} \mathrm{S}_{\mathrm{CCS}}\end{array}$ & $\begin{array}{l}\text { AQZ. } \\
\text { DQ)-QZ. } \\
\text { DQ)-AQZ. } \\
\text {-QZ. } \\
\text { AQZ. } \\
\text { (T)-QZ. } \\
\text { (T)-AQZ. }\end{array}$ & & & & \\
\hline
\end{tabular}

TABLE VIII. FPA of the vertical singlet-triplet gaps of naphthalene. "Well-to-well" $\mathrm{S}_{0}-\mathrm{T}_{1}$ excitation energies $\left(\mathrm{WWE}_{\mathrm{S}-\mathrm{T}}\right.$ ) results are correspondingly given in parentheses (all results are given in $\mathrm{kcal} / \mathrm{mol}$ ).

\begin{tabular}{|c|c|c|c|c|c|c|c|c|}
\hline \multicolumn{9}{|c|}{ Naphthalene } \\
\hline No. basis & $\begin{array}{c}\text { cc-pVDZ } \\
180\end{array}$ & $\begin{array}{c}\text { cc-pVTZ } \\
412\end{array}$ & $\begin{array}{c}\text { cc-pVQZ } \\
790\end{array}$ & $\begin{array}{c}\text { cc-pV5Z } \\
1350\end{array}$ & $\begin{array}{c}\text { aug-cc-pVDZ } \\
302\end{array}$ & F/S-QZ & F/S-AQZ & F/S-5Z \\
\hline$\Delta \mathrm{HF}$ & $\begin{array}{c}69.27 \\
(50.69)\end{array}$ & $\begin{array}{c}68.18 \\
(50.57)\end{array}$ & $\begin{array}{c}67.88 \\
(50.45)\end{array}$ & $\begin{array}{c}67.71 \\
(50.40)\end{array}$ & $\begin{array}{c}68.13 \\
(-)\end{array}$ & $\begin{array}{c}67.76^{\mathrm{a}} \\
(50.38)^{\mathrm{a}}\end{array}$ & $\begin{array}{c}67.64^{\mathrm{b}} \\
(-)\end{array}$ & $\begin{array}{c}67.63^{\mathrm{c}} \\
(50.38)^{\mathrm{c}}\end{array}$ \\
\hline$+\mathrm{MP} 2$ & $\begin{array}{c}21.91 \\
(32.04)\end{array}$ & $\begin{array}{c}22.83 \\
(34.04)\end{array}$ & $\begin{array}{c}23.24 \\
(34.72)\end{array}$ & $\begin{array}{l}23.40 \\
(34.92)\end{array}$ & $\begin{array}{c}22.36 \\
(-)\end{array}$ & $\begin{array}{c}23.34^{\mathrm{d}} \\
(34.88)^{\mathrm{d}}\end{array}$ & $\begin{array}{c}23.36^{\mathrm{e}} \\
(-)\end{array}$ & $\begin{array}{l}23.57^{\mathrm{f}} \\
(35.10)^{\mathrm{f}}\end{array}$ \\
\hline +MP3 & $\begin{array}{c}-7.50 \\
(-11.81)\end{array}$ & $\begin{array}{c}-8.34 \\
(-12.92)\end{array}$ & $\begin{array}{c}-8.59 \\
(-13.26)\end{array}$ & & $\begin{array}{c}-7.64 \\
(-)\end{array}$ & & & \\
\hline +MP4(SDQ) & $\begin{array}{c}-3.97 \\
(-4.64)\end{array}$ & $\begin{array}{c}-4.25 \\
(-5.04)\end{array}$ & $\begin{array}{c}-4.36 \\
(-5.21)\end{array}$ & & $\begin{array}{c}-4.25 \\
(-)\end{array}$ & & & \\
\hline$+\mathrm{CCSD}$ & $\begin{array}{c}-0.03 \\
(-0.55)\end{array}$ & $\begin{array}{c}0.60 \\
(0.19)\end{array}$ & & & $\begin{array}{l}0.19 \\
(-)\end{array}$ & & & \\
\hline$+\operatorname{CCSD}(\mathrm{T})$ & $\begin{array}{l}-2.66 \\
(-1.12)\end{array}$ & $\begin{array}{l}-2.56 \\
(-1.02)\end{array}$ & & & $\begin{array}{c}-2.56 \\
(-)\end{array}$ & & & \\
\hline$\Delta \operatorname{CCSD}(\mathrm{T})$ & $\begin{array}{c}77.03 \\
(64.62)\end{array}$ & $\begin{array}{c}76.46 \\
(65.82)\end{array}$ & & & $\begin{array}{c}76.22 \\
(-)\end{array}$ & & & \\
\hline$\Delta \operatorname{CASSCF}(10,10)$ & 71.62 & 71.61 & & & & & & \\
\hline$\Delta$ CASPT2 & 71.10 & 70.03 & & & & & & \\
\hline $\begin{array}{l}{ }^{\mathrm{a}} \mathrm{F}-\mathrm{QZ} . \\
{ }^{\mathrm{b}} \mathrm{F}-\mathrm{AQZ} . \\
{ }^{\mathrm{c}} \mathrm{F}-5 .\end{array}$ & & & & $\begin{array}{l}{ }^{{ }^{d}} S_{M P 2} \\
{ }^{e} S_{M P 2} \\
{ }^{\mathrm{f}} S_{M P 2}\end{array}$ & & & & \\
\hline
\end{tabular}


TABLE IX. FPA of the vertical singlet-triplet gaps of anthracene. "Well-to-well" $\mathrm{S}_{0}-\mathrm{T}_{1}$ excitation energies (WWE $\mathrm{S}_{-\mathrm{T}}$ ) results are correspondingly given in parentheses (all results are given in $\mathrm{kcal} / \mathrm{mol}$ ).

\begin{tabular}{|c|c|c|c|c|c|c|c|c|c|c|}
\hline & & & & & Anthracene & & & & & \\
\hline No. basis & $\begin{array}{c}\text { cc-pVDZ } \\
246\end{array}$ & $\begin{array}{c}\text { cc-pVTZ } \\
560\end{array}$ & $\begin{array}{c}\text { cc-pVQZ } \\
1070\end{array}$ & $\begin{array}{c}\text { cc-pV5Z } \\
1824\end{array}$ & $\begin{array}{c}\text { aug-cc-pVDZ } \\
412\end{array}$ & $\begin{array}{c}\text { aug-cc-pVTZ } \\
874\end{array}$ & $\begin{array}{c}\text { aug-cc-pVQZ } \\
1580\end{array}$ & F/S-QZ & F/S-AQZ & $\mathrm{F} / \mathrm{S}-5 \mathrm{Z}$ \\
\hline$\Delta \mathrm{HF}$ & $\begin{array}{l}44.68 \\
(30.83)\end{array}$ & $\begin{array}{l}44.02 \\
(30.91)\end{array}$ & $\begin{array}{c}43.83 \\
(30.82)\end{array}$ & $\begin{array}{c}43.74 \\
(30.79)\end{array}$ & $\begin{array}{l}44.05 \\
(-)\end{array}$ & $\begin{array}{l}43.79 \\
(-)\end{array}$ & $\begin{array}{c}43.73 \\
(-)\end{array}$ & $\begin{array}{c}43.76^{\mathrm{a}} \\
(30.74)^{\mathrm{a}}\end{array}$ & $\begin{array}{c}43.72^{\mathrm{b}} \\
(-)\end{array}$ & $\begin{array}{c}43.70^{\mathrm{c}} \\
(30.77)^{\mathrm{c}}\end{array}$ \\
\hline +MP2 & $\begin{array}{c}18.63 \\
(25.67)\end{array}$ & $\begin{array}{l}19.26 \\
(27.26)\end{array}$ & $\begin{array}{l}19.66 \\
(27.89)\end{array}$ & $\begin{array}{l}19.85 \\
(28.14)\end{array}$ & $\begin{array}{c}18.99 \\
(-)\end{array}$ & $\begin{array}{l}19.44 \\
(-)\end{array}$ & $\begin{array}{c}19.75 \\
(-)\end{array}$ & $\begin{array}{c}19.76^{\mathrm{d}} \\
(28.06)^{\mathrm{d}}\end{array}$ & $\begin{array}{c}19.82^{\mathrm{e}} \\
(-)\end{array}$ & $\begin{array}{l}20.02^{\mathrm{f}} \\
(28.35)^{\mathrm{f}}\end{array}$ \\
\hline$+\mathrm{MP} 3$ & $\begin{array}{c}-4.23 \\
(-7.68)\end{array}$ & $\begin{array}{c}-5.02 \\
(-8.74)\end{array}$ & & & $\begin{array}{c}-4.54 \\
(-)\end{array}$ & $\begin{array}{c}-5.13 \\
(-)\end{array}$ & & & & \\
\hline +MP4(SDQ) & $\begin{array}{l}-2.39 \\
(-3.13)\end{array}$ & $\begin{array}{l}-2.56 \\
(-3.44)\end{array}$ & & & $\begin{array}{c}-2.64 \\
(-)\end{array}$ & $\begin{array}{c}-2.67 \\
(-)\end{array}$ & & & & \\
\hline$+\mathrm{CCSD}$ & $\begin{array}{c}1.05 \\
(0.89)\end{array}$ & & & & $\begin{array}{l}1.23 \\
(-)\end{array}$ & & & & & \\
\hline$+\operatorname{CCSD}(\mathrm{T})$ & $\begin{array}{r}-0.33 \\
(0.52)\end{array}$ & & & & $\begin{array}{c}-0.36 \\
(-)\end{array}$ & & & & & \\
\hline$\Delta \operatorname{CCSD}(\mathrm{T})$ & $\begin{array}{c}57.40 \\
(47.10)\end{array}$ & & & & $\begin{array}{l}56.73 \\
(-)\end{array}$ & & & & & \\
\hline$\Delta \mathrm{CASSCF}(14,14)$ & 54.00 & 54.03 & & & & & & & & \\
\hline$\Delta$ CASPT2 & 50.34 & 49.39 & & & & & & & & \\
\hline
\end{tabular}

active space, which was incomplete.

In view of possible couplings with Rydberg states and/or with the continuum, assessing the influence of diffuse functions in the basis set on frontier orbitals and related properties is always a mandatory step in accurate computations of excited state properties. The computed vertical excitation energies for benzene and the next six terms of the acene series are around 101, 76, 57, 41, 32, and $22 \mathrm{kcal} / \mathrm{mol}$ (according to

TABLE X. FPA of the vertical singlet-triplet gaps of naphthacene. "Wellto-well" $\mathrm{S}_{0}-\mathrm{T}_{1}$ excitation energies $\left(\mathrm{WWE}_{\mathrm{S}-\mathrm{T}}\right)$ results are correspondingly given in parentheses (all results are given in $\mathrm{kcal} / \mathrm{mol}$ ).

\begin{tabular}{|c|c|c|c|c|}
\hline \multicolumn{5}{|c|}{ Naphthacene } \\
\hline No. basis & $\begin{array}{c}\text { cc-pVDZ } \\
312\end{array}$ & $\begin{array}{c}\text { cc-pVTZ } \\
708\end{array}$ & $\begin{array}{l}\text { cc-pVQZ } \\
1350\end{array}$ & F/S-QZ \\
\hline$\Delta \mathrm{HF}$ & $\begin{array}{c}25.05 \\
(13.09)\end{array}$ & $\begin{array}{c}24.53 \\
(13.20)\end{array}$ & $\begin{array}{c}24.40 \\
(13.15)\end{array}$ & $\begin{array}{c}24.36^{\mathrm{a}} \\
(13.09)^{\mathrm{a}}\end{array}$ \\
\hline +MP2 & $\begin{array}{c}29.35 \\
(35.76)\end{array}$ & $\begin{array}{c}30.30 \\
(37.39)\end{array}$ & $\begin{array}{c}30.79 \\
(38.05)\end{array}$ & $\begin{array}{c}30.91^{\mathrm{b}} \\
(38.23)^{\mathrm{b}}\end{array}$ \\
\hline +MP3 & $\begin{array}{c}-7.74 \\
(-10.32)\end{array}$ & $\begin{array}{c}-8.96 \\
(-11.81)\end{array}$ & & \\
\hline +MP4(SDQ) & $\begin{array}{c}-4.13 \\
(-4.77)\end{array}$ & $\begin{array}{c}-4.49 \\
(-5.23)\end{array}$ & & \\
\hline$+\mathrm{CCSD}$ & $\begin{array}{c}-0.27 \\
(-0.56)\end{array}$ & & & \\
\hline$+\operatorname{CCSD}(\mathrm{T})$ & $\begin{array}{c}-1.06 \\
(-0.16)\end{array}$ & & & \\
\hline$\Delta \operatorname{CCSD}(\mathrm{T})$ & $\begin{array}{c}41.19 \\
(33.05)\end{array}$ & & & \\
\hline$\Delta \mathrm{CASSCF}(14,14)$ & 38.93 & 38.96 & & \\
\hline$\Delta$ CASPT2 & 35.29 & 34.50 & & \\
\hline
\end{tabular}

${ }^{\mathrm{a}} \mathrm{F}-\mathrm{QZ}$.

${ }^{\mathrm{b}} \mathrm{S}_{\mathrm{MP} 2}-\mathrm{QZ}$ our best FPA estimates), and lie thus much below the ionization threshold, which is correspondingly located at 218,190 , $172,160,152$, and $148 \mathrm{kcal} / \mathrm{mol}^{17}$ In line with our former works on ionization energies ${ }^{17}$ and electron affinities, ${ }^{18}$ we do not except therefore that the inclusion of diffuse functions in the basis sets would significantly affect the extrapolation of triplet excitation energies toward the limit of asymptotically complete cc-pVœZ basis sets. The excitation energies

TABLE XI. FPA of the vertical singlet-triplet gaps of pentacene. "Well-towell" $\mathrm{S}_{0}-\mathrm{T}_{1}$ excitation energies $\left(\mathrm{WWE}_{\mathrm{S}-\mathrm{T}}\right)$ results are correspondingly given in parentheses (all results are given in $\mathrm{kcal} / \mathrm{mol}$ ).

\begin{tabular}{|c|c|c|c|c|}
\hline \multicolumn{5}{|c|}{ Pentacene } \\
\hline No. basis & $\begin{array}{c}\text { cc-pVDZ } \\
378\end{array}$ & $\begin{array}{c}\text { cc-pVTZ } \\
856\end{array}$ & $\begin{array}{l}\text { cc-pVQZ } \\
1630\end{array}$ & F/S-QZ \\
\hline$\Delta \mathrm{HF}$ & $\begin{array}{l}11.50 \\
(0.46)\end{array}$ & $\begin{array}{l}11.02 \\
(0.49)\end{array}$ & $\begin{array}{l}10.91 \\
(0.44)\end{array}$ & $\begin{array}{l}10.88^{\mathrm{a}} \\
(0.40)^{\mathrm{a}}\end{array}$ \\
\hline +MP2 & $\begin{array}{c}34.11 \\
(42.53)\end{array}$ & $\begin{array}{c}35.36 \\
(44.40)\end{array}$ & $\begin{array}{c}35.94 \\
(45.13)\end{array}$ & $\begin{array}{c}36.09^{\mathrm{b}} \\
(45.31)^{\mathrm{b}}\end{array}$ \\
\hline +MP3 & $\begin{array}{c}-9.07 \\
(-12.44)\end{array}$ & $\begin{array}{c}-10.54 \\
(-14.28)\end{array}$ & & \\
\hline +MP4(SDQ) & $\begin{array}{c}-4.83 \\
(-5.96)\end{array}$ & $\begin{array}{c}-5.34 \\
(-6.60)\end{array}$ & & \\
\hline$+\mathrm{CCSD}$ & $\begin{array}{c}0.08 \\
(-0.69)\end{array}$ & & & \\
\hline$+\operatorname{CCSD}(\mathrm{T})$ & $\begin{array}{c}0.21 \\
(1.06)\end{array}$ & & & \\
\hline$\Delta \operatorname{CCSD}(\mathrm{T})$ & $\begin{array}{l}31.99 \\
(24.95)\end{array}$ & & & \\
\hline$\Delta \mathrm{CASSCF}(14,14)$ & 29.96 & 30.07 & & \\
\hline$\Delta$ CASPT2 & 24.92 & 24.19 & & \\
\hline
\end{tabular}


TABLE XII. FPA of the vertical singlet-triplet gaps of hexacene. "Well-towell" $\mathrm{S}_{0}-\mathrm{T}_{1}$ excitation energies $\left(\mathrm{WWE}_{\mathrm{S}-\mathrm{T}}\right)$ results are correspondingly given in parentheses (all results are given in $\mathrm{kcal} / \mathrm{mol}$ ).

\begin{tabular}{|c|c|c|c|c|}
\hline \multicolumn{5}{|c|}{ Hexacene } \\
\hline No. basis & $\begin{array}{c}\text { cc-pVDZ } \\
444\end{array}$ & $\begin{array}{l}\text { cc-pVTZ } \\
1004\end{array}$ & $\begin{array}{l}\text { cc-pVQZ } \\
1910\end{array}$ & F/S-QZ \\
\hline$\Delta \mathrm{HF}$ & $\begin{array}{c}0.18 \\
(-9.92)\end{array}$ & $\begin{array}{c}-0.28 \\
(-9.96)\end{array}$ & $\begin{array}{c}-0.37 \\
(-10.01)\end{array}$ & $\begin{array}{c}-0.38^{\mathrm{a}} \\
(-10.05)^{\mathrm{a}}\end{array}$ \\
\hline +MP2 & $\begin{array}{c}40.59 \\
(49.29)\end{array}$ & $\begin{array}{c}42.08 \\
(51.38)\end{array}$ & $\begin{array}{c}42.74 \\
(52.19)\end{array}$ & $\begin{array}{c}42.90^{\mathrm{b}} \\
(52.39)^{\mathrm{b}}\end{array}$ \\
\hline$+\mathrm{MP} 3$ & $\begin{array}{c}-11.05 \\
(14.55)\end{array}$ & $\begin{array}{c}-12.78 \\
(-16.69)\end{array}$ & & \\
\hline +MP4(SDQ) & $\begin{array}{c}-5.69 \\
(-6.90)\end{array}$ & $\begin{array}{c}-6.35 \\
(-7.72)\end{array}$ & & \\
\hline$+\mathrm{CCSD}$ & $\begin{array}{l}-0.72 \\
(-1.41)\end{array}$ & & & \\
\hline$+\operatorname{CCSD}(\mathrm{T})$ & $\begin{array}{c}0.23 \\
(1.08)\end{array}$ & & & \\
\hline$\Delta \operatorname{CCSD}(\mathrm{T})$ & $\begin{array}{c}23.53 \\
(17.60)\end{array}$ & & & \\
\hline$\triangle \mathrm{CASSCF}(14,14)$ & 21.90 & 21.97 & & \\
\hline$\Delta$ CASPT2 & 18.59 & 17.95 & & \\
\hline
\end{tabular}

${ }^{\mathrm{a}} \mathrm{F}-\mathrm{QZ}$.

${ }^{\mathrm{b}} \mathrm{S}_{\mathrm{MP2} 2}-\mathrm{QZ}$.

obtained using the cc-pVœZ and aug-cc-pVœZ basis sets indeed do not differ by more than $0.3 \mathrm{kcal} / \mathrm{mol}$ (see results in Table XIV).

The trends emerging from our calculations on the first seven terms of the $n$-acene series are clear enough to enable semiquantitative extrapolations to much longer acenes. In view of the dominance of second order dynamical correlation, it is rather obvious that the singlet closed-shell state will

TABLE XIII. FPA of the vertical singlet-triplet gaps of heptacene. "Wellto-well" $\mathrm{S}_{0}-\mathrm{T}_{1}$ excitation energies $\left(\mathrm{WWE}_{\mathrm{S}-\mathrm{T}}\right)$ results are correspondingly given in parentheses (all results are given in $\mathrm{kcal} / \mathrm{mol}$ ).

\begin{tabular}{|c|c|c|c|c|}
\hline \multicolumn{5}{|c|}{ Heptacene } \\
\hline No. basis & $\begin{array}{c}\text { cc-pVDZ } \\
510\end{array}$ & $\begin{array}{l}\text { cc-pVTZ } \\
1152\end{array}$ & $\begin{array}{l}\text { cc-pVQZ } \\
2190\end{array}$ & F/S-QZ \\
\hline$\Delta \mathrm{HF}$ & $\begin{array}{c}-8.69 \\
(-18.39)\end{array}$ & $\begin{array}{c}-9.17 \\
(-18.54)\end{array}$ & $\begin{array}{c}-9.26 \\
(-18.60)\end{array}$ & $\begin{array}{c}-9.28^{\mathrm{a}} \\
(-18.63)^{\mathrm{a}}\end{array}$ \\
\hline +MP2 & $\begin{array}{c}49.20 \\
(58.50)\end{array}$ & $\begin{array}{c}51.10 \\
(60.93)\end{array}$ & $\begin{array}{c}51.86 \\
(61.83)\end{array}$ & $\begin{array}{c}52.05^{\mathrm{b}} \\
(62.05)^{\mathrm{b}}\end{array}$ \\
\hline +MP3 & $\begin{array}{c}-14.04 \\
(-17.70)\end{array}$ & $\begin{array}{c}-16.15 \\
(-20.26)\end{array}$ & & \\
\hline +MP4(SDQ) & $\begin{array}{c}-7.37 \\
(-8.62)\end{array}$ & $\begin{array}{c}-8.25 \\
(-9.65)\end{array}$ & & \\
\hline$+\mathrm{CCSD}$ & $\begin{array}{l}-1.41 \\
(-2.28)\end{array}$ & & & \\
\hline$+\operatorname{CCSD}(\mathrm{T})$ & $\begin{array}{c}1.16 \\
(2.03)\end{array}$ & & & \\
\hline$\Delta \operatorname{CCSD}(\mathrm{T})$ & $\begin{array}{c}18.86 \\
(13.54)\end{array}$ & & & \\
\hline$\Delta \operatorname{CASSCF}(14,14)$ & 18.31 & 18.32 & & \\
\hline$\Delta$ CASPT2 & 16.39 & 15.92 & & \\
\hline
\end{tabular}

TABLE XIV. Estimates of the vertical singlet-triplet gaps (all results are given in $\mathrm{kcal} / \mathrm{mol}$ ). "Well-to-well" $\mathrm{S}_{0}-\mathrm{T}_{1}$ excitation energies $\left(\mathrm{WWE}_{\mathrm{S}-\mathrm{T}}\right.$ ) results are correspondingly given in parentheses. Best estimates are in boldface.

\begin{tabular}{lcccc}
\hline \hline & FPA_QZ & FPA_AQZ & FPA_5Z & FPA_5Z2 \\
\hline Benzene & 103.71 & 103.90 & 103.67 & $\mathbf{1 0 4 . 3 7}$ \\
& $(91.58)$ & $(-)$ & $(91.78)$ & $\mathbf{( 9 2 . 2 2 )}$ \\
Naphthalene & 75.83 & 75.96 & 75.92 & $\mathbf{7 6 . 2 8}$ \\
Anthracene & $(65.63)$ & $(-)$ & $(65.84)$ & $(\mathbf{6 6 . 1 8})$ \\
& 56.65 & 56.61 & 56.86 & $\mathbf{5 6 . 9 7}$ \\
Naphthacene & $(48.02)$ & $(-)$ & $(48.34)$ & $\mathbf{( 4 8 . 5 1}^{\mathrm{b}}$ \\
& 40.49 & $40.68^{\mathrm{c}}$ & $40.77^{\mathrm{d}}$ & $\mathbf{4 0 . 6 9}$ \\
Pentacene & $(33.57)$ & $(-)$ & $(33.90)^{\mathrm{e}}$ & $\mathbf{( 3 4 . 0 1}^{\mathrm{b}}$ \\
Hexacene & 31.37 & $31.51^{\mathrm{c}}$ & $31.70^{\mathrm{d}}$ & $\mathbf{3 1 . 5 1}$ \\
& $(25.19)$ & $(-)$ & $(25.55)^{\mathrm{a}}$ & $\mathbf{( 2 5 . 6 1}^{\mathrm{b}}$ \\
Heptacene & 22.89 & $22.96^{\mathrm{c}}$ & $23.26^{\mathrm{d}}$ & $\mathbf{2 2 . 9 6}^{\mathrm{a}}$ \\
& $(17.61)$ & $(-)$ & $(17.98)^{\mathrm{e}}$ & $\mathbf{( 1 8 . 0 0}^{\mathrm{b}}$ \\
& 18.12 & $18.16^{\mathrm{c}}$ & $18.52^{\mathrm{b}}$ & $\mathbf{1 8 . 1 6}^{\mathrm{a}}$ \\
& $(13.26)$ & $(-)$ & $(13.64)^{\mathrm{e}}$ & $\mathbf{( 1 3 . 6 3}^{\mathrm{b}}$ \\
\hline
\end{tabular}

${ }^{\mathrm{a}}$ Extrapolated results; FPA_5Z2=1.0072FPA_QZ-0.0946.

${ }^{\mathrm{b}}$ Extrapolated results; FPA_5Z2 $=1.0035 \mathrm{FPA} \_\mathrm{QZ}+0.3246$

${ }^{\mathrm{c}}$ Extrapolated results; FPA_AQZ $=1.0047 \mathrm{FPA} \_\mathrm{QZ}-0.2776$.

${ }^{\mathrm{d}}$ Extrapolated results; FPA_5Z $=0.9949 \mathrm{FPA} \_\mathrm{QZ}+0.4874$.

${ }^{\mathrm{e}}$ Extrapolated results; FPA_5Z=0.9976FPA_QZ+0.4146.

remain the electronic ground state of much larger members in the series. In Table XV, we describe linear correlations of benchmark FPA_QZ results for singlet-triplet energy gaps with estimates obtained at lower levels, MP3/cc-pVDZ, MP4SDQ/cc-pVDZ, CCSD/cc-pVDZ, and CCSD(T)/ccpVDZ, respectively. Clearly, an improvement in the quality of the regression is to be related with a convergence of the treatment of electronic correlation. A preliminary $\operatorname{CCSD}(\mathrm{T}) / \mathrm{cc}-\mathrm{pV} \infty \mathrm{Z}$ estimates of $14.29 \mathrm{kcal} / \mathrm{mol}$, amounting to a dual extrapolation by means of the FPA_QZ protocol, can for instance be derived from a CCSD/cc-pVDZ//B3LYP/ cc-pVTZ value of $14.18 \mathrm{kcal} / \mathrm{mol}$ for the vertical ST-gap of octacene.

Similar observations can be made upon correlating various FPA results. Indeed, a three point extrapolation based on the FPA_QZ and FPA_AQZ results obtained for benzene, naphthalene, and anthracene yields the following regression formula: FPA_AQZ $=1.0047^{*} \mathrm{FPA} \_\mathrm{QZ}-0.2776$ $\left(\mathrm{R}^{2}=1.00000\right)$. Similarly, FPA_5Z values can be estimated

TABLE XV. Correlation between FPA_QZ and lower level methods, according to the fit of the form FPA_QZ=A*method+B. "Well-to-well" $\left(\mathrm{WWE}_{\mathrm{S}-\mathrm{T}}\right)$ results are correspondingly given in parentheses.

\begin{tabular}{lccc}
\hline \hline Method & $\mathrm{A}$ & $\mathrm{B}$ & $\mathrm{R}^{2}$ \\
\hline MP2/cc-pVDZ & 0.9629 & -13.625 & 0.9709 \\
& $(1.1287)$ & $(-18.088)$ & $(0.9587)$ \\
MP3/cc-pVDZ & 0.9731 & -5.0972 & 0.9951 \\
& $(0.9635)$ & $(6.9982)$ & $(0.9929)$ \\
MP4SDQ/cc-pVDZ & 0.9553 & 0.4489 & 0.9989 \\
& $(1.0047)$ & $(-0.2710)$ & $(0.9986)$ \\
CCSD/cc-pVDZ & 0.9690 & 0.3230 & 0.9990 \\
& $(0.9986)$ & $(-1.0725)$ & $(0.9993)$ \\
CCSD(T)/cc-pVDZ & 0.9878 & 0.2912 & 1.0000 \\
& $(0.9772)$ & $(0.3772)$ & $(1.0000)$ \\
\hline \hline
\end{tabular}


TABLE XVI. Calculated and experimental singlet-triplet energy gaps, along with zero-point vibrational energy ( $\Delta$ ZPE) and geometry relaxation (GRXE) contributions. All results are given in $\mathrm{kcal} / \mathrm{mol}$.

\begin{tabular}{|c|c|c|c|c|c|c|c|c|}
\hline & $\mathrm{VE}_{\mathrm{S}-\mathrm{T}}$ & $\mathrm{WWE}_{\mathrm{S}-\mathrm{T}}$ & $\mathrm{WWE}_{\mathrm{S}-\mathrm{T}}$ & GRXE & GRXE & $\Delta \mathrm{ZPE}$ & $\mathrm{AE}_{\mathrm{S}-\mathrm{T}}$ & \\
\hline & $\begin{array}{l}\operatorname{CCSD}(\mathrm{T}) / \\
\mathrm{cc}-\mathrm{pV} \propto \mathrm{Z}^{\mathrm{a}}\end{array}$ & $\begin{array}{l}\operatorname{CCSD}(\mathrm{T}) / \\
\text { cc-pV } \infty \mathrm{Z}^{\mathrm{a}}\end{array}$ & $\begin{array}{l}\text { CASCI/ } \\
\text { cc-pVDZ }\end{array}$ & $\begin{array}{l}\operatorname{CCSD}(\mathrm{T}) / \\
\mathrm{cc}-\mathrm{pV} \propto \mathrm{Z}^{\mathrm{a}, \mathrm{c}}\end{array}$ & $\begin{array}{l}\text { B3LYP// } \\
\text { cc-pV } \infty Z^{d}\end{array}$ & $\begin{array}{l}\text { B3LYP/ } \\
\text { cc-pVTZ }\end{array}$ & $\begin{array}{l}\operatorname{CCSD}(\mathrm{T}) / \\
\mathrm{cc}-\mathrm{pV} \propto \mathrm{Z}^{\mathrm{a}, \mathrm{e}}\end{array}$ & Experimental \\
\hline Benzene & $100.79^{\mathrm{f}}$ & 92.22 & $\ldots$ & -12.15 & -14.10 & -5.20 & 87.02 & $84.34^{\mathrm{g}}$ \\
\hline Naphthalene & 76.28 & 66.18 & 61.0 & -10.10 & -9.98 & -3.31 & 62.87 & $60.90,{ }^{\mathrm{h}} 61.00$ \\
\hline Anthracene & 56.97 & 48.51 & 44.0 & -8.46 & -7.58 & -2.29 & 46.22 & $42.60,{ }^{j} 43.10^{k}$ \\
\hline Naphthacene & 40.69 & 34.01 & 31.9 & -6.68 & -6.13 & -1.78 & 32.23 & $29.45^{1}$ \\
\hline Pentacene & 31.51 & 25.61 & 23.4 & -5.90 & -5.15 & -1.42 & 24.19 & $19.83 \pm 0.70^{\mathrm{m}}$ \\
\hline Hexacene & 22.96 & 18.00 & 17.5 & -4.96 & -4.41 & -1.21 & 16.79 & $12.43 \pm 1.20^{\mathrm{n}}$ \\
\hline Heptacene & 18.16 & 13.63 & $\ldots$ & -4.53 & -3.93 & -1.07 & 12.56 & \\
\hline
\end{tabular}

${ }^{\mathrm{a}}$ FPA_5Z2 estimate (see methodology section for details).

${ }^{\mathrm{b}}$ From Ref. 13.

${ }^{\mathrm{c}}$ Calculated from the differences between the $\mathrm{WWE}_{\mathrm{S}-\mathrm{T}}$ FPA and $\mathrm{VE}_{\mathrm{S}-\mathrm{T}}$ FPA data.

${ }^{\mathrm{d}} \mathrm{F}_{\mathrm{B} 3 \mathrm{LYP}}-\mathrm{QZ}$ estimate.

${ }^{\mathrm{e}}$ Upon adding $\triangle \mathrm{ZPE}$ corrections to $\mathrm{WWE}_{\mathrm{S}-\mathrm{T}} \mathrm{CCSD}(\mathrm{T}) / \mathrm{cc}-\mathrm{pV} \propto \mathrm{Z}$ data.

${ }^{\mathrm{f}}$ Symmetry-corrected result, the noncorrected (symmetry-broken) value is $104.37 \mathrm{kcal} / \mathrm{mol}$.

${ }^{\mathrm{g}} \mathrm{In}$ argon or methane matrix at $4 \mathrm{~K}$, for details see Ref. 33 and references therein.

${ }^{\mathrm{h}}$ In ether-isopentane-alcohol or related (solid) solvents (EPA+) at $77 \mathrm{~K}$, for details see Ref. 33 and references therein.

${ }^{\mathrm{i}}$ From Ref. 34 (no experimental details were provided).

${ }^{\mathrm{j}}$ In ether-isopentane-alcohol or related (solid) solvents (EPA+) at $77 \mathrm{~K}$, for details see Ref. 33 and references therein.

${ }^{\mathrm{k}}$ Value obtained from laser-detachment photoelectron spectroscopy experiments in the gas phase on the anion (Ref. 35). This value was determined as the difference between the anion to neutral singlet and the anion to neutral triplet transition energies and corresponds thus to the $\mathrm{S}_{0}-\mathrm{T}_{1}$ excitation energy of the neutral within the geometry of the anion.

${ }^{1}$ Measured in a polymethylmethacrylate matrix at room temperature, see Ref. 33 and references therein for details.

${ }^{\mathrm{m}}$ Measured in a naphthacene matrix at room temperature, see Ref. 95 for details.

${ }^{n}$ Measured in silicone oil at room temperature, see Ref. 11 for details.

from the FPA_QZ and FPA_5Z results of benzene, naphthalene, and anthracene according to the regression FPA_5Z $=0.9949 *$ FPA_QZ $+0.4874 \quad\left(\mathrm{R}^{2}=1.00000\right) . \quad$ Finally, FPA_5Z2 values can be inferred from the FPA_QZ and FPA_5Z2 results for benzene, and naphthalene, and related to lower-level results by the equation FPA_5Z2 $=1.0072^{*}$ FPA_QZ-0.0946 (Table XIV). It is worth noticing that the discrepancies between the different FPA results for the vertical $\mathrm{S}_{0}-\mathrm{T}_{1}$ excitation energies of benzene and acenes do not exceed $0.70,0.45,0.36,0.28,0.33,0.37$, and $0.40 \mathrm{kcal} / \mathrm{mol}$, when $n=1-7$, respectively, indicating convergence of our treatment of electronic correlation within chemical $(1 \mathrm{kcal} / \mathrm{mol})$ accuracy. The best (FPA_5Z2) estimates for the vertical singlet-triplet energy gaps $\left(\mathrm{VE}_{\mathrm{S}-\mathrm{T}}\right)$ of naphthalene, anthracene, naphthacene, pentacene, hexacene, and heptacene are, therefore, 76.28, 56.97, 40.69, 31.51, 22.96 , and $18.16 \mathrm{kcal} / \mathrm{mol}$, respectively (Table XV). Our best estimation for the S-T energy gap of benzene is $100.79 \mathrm{kcal} /$ mol. This value was derived by adding to the best FPA (FPA_5Z2) estimate of $104.37 \mathrm{kcal} / \mathrm{mol}$ the [MRAQCC $(4,4) /$ aug-cc-pVQZ] correction of $-3.57 \mathrm{kcal} / \mathrm{mol}$ for the symmetry breaking of the electronic density.

\section{Well-to-well and adiabatic singlet-triplet gaps}

The principles of the FPA have been extended to "wellto-well" and adiabatic excitation energies as well, by running all necessary single-point calculations on geometries optimized at the B3LYP/cc-pVTZ level for the triplet excited states. In our revision, adiabatic geometrical relaxation energies (GRXE) were thus estimated in the limit of a $\mathrm{CCSD}(\mathrm{T}) / \mathrm{cc}-\mathrm{pV} \infty \mathrm{Z}$ [FPA_5Z2] treatment (Table XVI), according to the energy differences at this level between the vertical and relaxed triplet excited state (see data in Table XIV). Improvements over the corresponding $\mathrm{B} 3 \mathrm{LYP} / \mathrm{cc}-\mathrm{pV} \infty \mathrm{Z}$ values are marginal, within $1 \mathrm{kcal} / \mathrm{mol}$, except in the case of benzene, which undergoes more complicated symmetry-breaking effects due to Jahn-Teller distortions from a nonabelian symmetry point group (Table $X V I)$. Details of the extrapolations of the B3LYP/cc-pVXZ $(X=\{D, T, Q\})$ relaxation energies to their asymptotic limit $(\mathrm{B} 3 \mathrm{LYP} / \mathrm{cc}-\mathrm{pV} \infty \mathrm{Z})$ are given in Table XVII. The largest increase in the relaxation energy due to the extension of the basis set from cc-pVTZ to cc-pV $\infty \mathrm{Z}$ is observed with benzene and amounts to $0.29 \mathrm{kcal} / \mathrm{mol}$ only.

As with the $\mathrm{VE}_{\mathrm{S}-\mathrm{T}}$ estimates, FPA_5Z and FPA_5Z2 values for the well-to-well singlet-triplet energy gaps can be estimated from the FPA_QZ results, using linear correlations of exceedingly high quality, namely, FPA_5Z $=0.9976{ }^{*}$ FPA_QZ $+0.4146\left(\mathrm{R}^{2}=1.00000\right)$, and FPA_5Z2 $=1.0035^{\circ}$ FPA_QZ+0.3246.

In line with the increased delocalization of the molecular orbitals, geometrical relaxation energies smoothly decrease with increasing system size due to the more extended delocalization of the involved orbitals. Correspondingly, the overall amplitude of the structural relaxation effects that are induced by a triplet excitation process decreases upon an increase in system size. Typically, the shorter $\mathrm{C}-\mathrm{C}$ bonds get longer whereas the longer $\mathrm{C}-\mathrm{C}$ bonds get shorter, while the $\mathrm{C}-\mathrm{H}$ bonds do not change significantly (Fig. 5). For instance the largest $\mathrm{C}-\mathrm{C}$ bond stretching is $0.126 \AA$ for benzene, $0.067 \AA$ for naphthalene, $0.045 \AA$ for anthracene, $0.039 \AA$ for naphthacene, $0.036 \AA$ for pentacene, $0.030 \AA$ for hexacene, and $0.024 \AA$ for heptacene. In contrast, the lengths 
TABLE XVII. Calculated and extrapolated geometrical relaxation energies (GRXE). All results are given in $\mathrm{kcal} / \mathrm{mol}$.

\begin{tabular}{lcccc}
\hline \hline & B3LYP/cc-pVDZ & B3LYP/cc-pVTZ & B3LYP/cc-pVQZ & B3LYP/cc-pV $\propto Z^{\mathrm{a}}$ \\
\hline Benzene & 14.33 & 14.39 & 14.23 & 14.10 \\
Naphthalene & 11.08 & 10.02 & 9.93 & 9.98 \\
Anthracene & 8.44 & 7.57 & 7.52 & 7.58 \\
Naphthacene & 6.81 & 6.12 & 6.08 & 6.13 \\
Pentacene & 5.69 & 5.14 & 5.11 & 5.15 \\
Hexacene & 4.83 & 4.39 & 4.37 & 4.41 \\
Heptacene & 4.27 & 3.91 & 3.90 & 3.93 \\
\hline \hline
\end{tabular}

${ }^{\mathrm{a}} \mathrm{F}_{\mathrm{B} 3 \mathrm{LYP}}-\mathrm{QZ}$ estimate.

of the longer $\mathrm{C}-\mathrm{C}$ bonds decrease by less than $0.009 \AA$ for benzene, $0.055 \AA$ for naphthalene, $0.044 \AA$ for anthracene, $0.035 \AA$ for naphthacene, $0.026 \AA$ for pentacene, $0.025 \AA$ for hexacene, and $0.024 \AA$ for heptacene. The less pronounced geometrical changes are usually found around the central ring(s) of the molecule.

Adding B3LYP/cc-pVTZ estimates for the ZPVEs corrections to the well-to-well excitation energies $\left(\mathrm{WWE}_{\mathrm{S}-\mathrm{T}}\right)$ yields the adiabatic ST energy gaps reported in Table XVI under the $\mathrm{AE}_{\mathrm{S}-\mathrm{T}}$ entry, which represent our best estimates for these energy differences. The changes induced at the B3LYP/ cc-pVTZ level by adiabatic triplet excitation processes onto the zero-point vibrational energies $(\triangle \mathrm{ZPE})$ are found to significantly decrease, by about $5.20 \mathrm{kcal} / \mathrm{mol}$, the adiabatic singlet-triplet energy gap of benzene (in its triplet state at equilibrium geometry, benzene exhibits a $\mathrm{C}_{2 \mathrm{~h}}$ symmetry, and possesses a ${ }^{3} B_{u}$ electronic wave function). Proceeding further through the linear acene series, we observe that the $\triangle \mathrm{ZPE}$

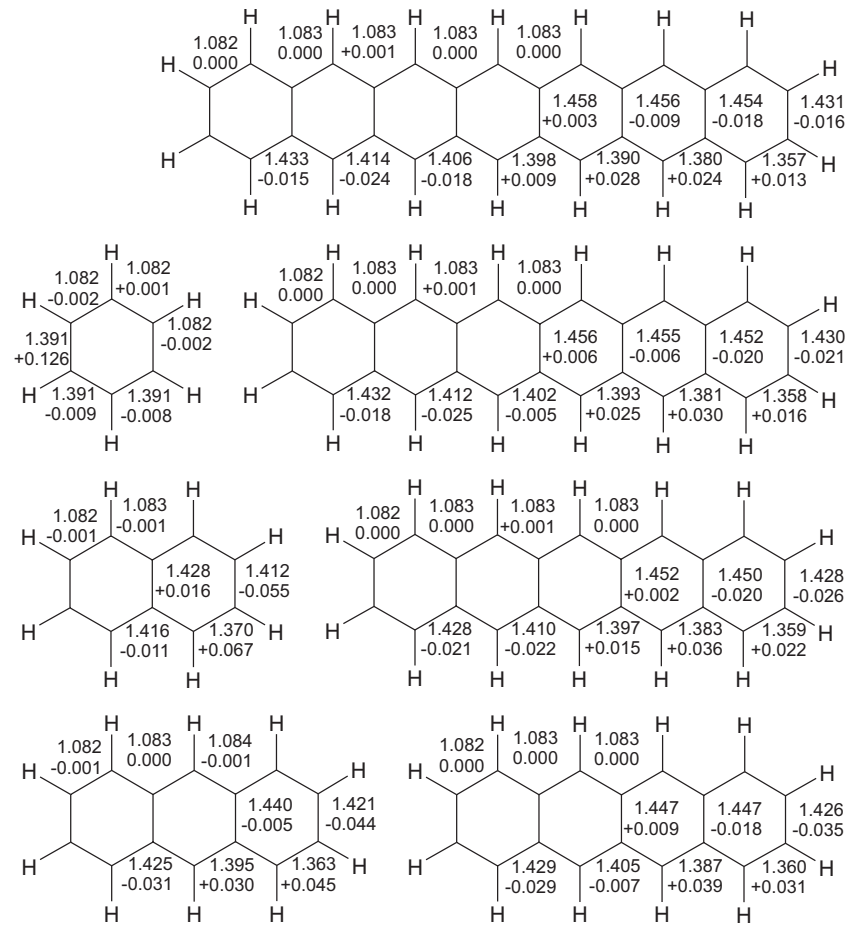

FIG. 5. Main geometry parameters of the investigated compounds (bond lengths in angstrom) and geometrical relaxations upon triplet excitation (in angstrom) at the B3LYP/cc-pVTZ level of theory. corrections closely follow the trends observed previously for the relaxation energies (GRXE values) and tend to vanish with increasing system size.

Our best estimates for the ST energy gaps of benzene and acenes at $0 \mathrm{~K}$ in vacuum systematically overestimate the available experimental values by $\sim 3$ to $\sim 4 \mathrm{kcal} / \mathrm{mol}$. This discrepancy is most probably ascribable to intermolecular interactions and packing effects in various environments (solutions, glassy matrices), residual defects in the employed B3LYP/cc-pVTZ geometries, zero-point vibrational and/or thermal distortions of the molecular structure, anharmonicities, vibronic coupling interactions, or to further geometrical complications in the case of photoelectron detachment experiments on mass-selected anions, as was for instance the case with anthracene. ${ }^{35}$ The main factor limiting the accuracy of the many-body calculations in vacuum is most probably not the solution of the electronic Schrödinger equation, but that of the nuclear Schrödinger equation. ${ }^{79}$ We note also for instance that bathochromic shifts as large as $0.089 \mathrm{eV}$ $(\sim 2 \mathrm{kcal} / \mathrm{mol})$ or $0.171 \mathrm{eV}(\sim 4 \mathrm{kcal} / \mathrm{mol})$ have been observed at the level of the absorption threshold in the UV-visible spectrum of naphthalene ${ }^{80}$ and anthracene ${ }^{81}$ when these compounds are trapped in zeolites.

Our benchmark CCSD(T)/cc-pV $\infty Z$ (FPA_5Z2) estimates for the well-to-well energy gaps $\left(\mathrm{WWE}_{\mathrm{S}-\mathrm{T}}\right)$ are significantly larger, by $\sim 1$ (hexacene) to $\sim 6 \mathrm{kcal} / \mathrm{mol}$ (naphthalene), than the CASCI/cc-pVDZ values provided for the same energy gaps by Hachmann et al. ${ }^{13}$ The excellent match, within $\sim 0.0$ (naphthalene) to $\sim 3.6 \mathrm{kcal} / \mathrm{mol}$ (pentacene), between the latter results and experiment was thus largely the result of error compensations, due to the neglect of zeropoint vibrational energies and limitations in the employed basis set and active space. According to results presented in the study by Hachmann et al. ${ }^{13}$ for naphthalene, it was concluded that the neglect of $\sigma$-space dynamic correlation should not significantly affect the singlet-triplet gap of larger systems, unless the active space is constructed from an incomplete $\pi$-valence space. We found the latter observation to be true in the case of naphthalene, upon comparing our CASSCF/cc-pVDZ (61.23 kcal/mol) and CASPT2/cc-pVDZ $(61.14 \mathrm{kcal} / \mathrm{mol}) \mathrm{results}$ for the well-to-well singlet-triplet gap of this compound. On the other hand, with a system still as small as anthracene, values of 44.87 and $41.90 \mathrm{kcal} / \mathrm{mol}$ are correspondingly obtained, demonstrating the increasing influence $(-2.96 \mathrm{kcal} / \mathrm{mol}$ already) of the second-order dy- 
namic correlation that is missing at the CAS-SCF level, compared to a CASPT2 calculation employing a complete $\pi$-valence space. Most likely, the influence of the missing dynamic correlation associated with $\sigma-\pi^{*}, \pi-\sigma^{*}$, and to a lesser extent, $\sigma-\sigma^{*}$ excitation contributions ought to increase with system size, in view of the expected sizeextensive scaling of dynamic electron correlation energies, and because of the progressive closure of the HOMO-LUMO $\pi-\pi^{*}$ band gap, along with the decrease and saturation thereby of the $\sigma-\pi^{*}, \pi-\sigma^{*}$, and $\sigma-\sigma^{*}$ band gaps to a finite limit. Note therefore that the error $(-2.96 \mathrm{kcal} / \mathrm{mol})$ arising from neglecting partially the dynamic correlation in the CAS type wave function seems to be comparable with the CASCI/ cc-pVDZ value of $+3.33 \mathrm{kcal} / \mathrm{mol}$ that was proposed for the well-to-well singlet-triplet energy gap when $n \rightarrow \infty$. $^{13}$

\section{Extrapolation to an infinite system}

In the work by Hachmann et al., ${ }^{13}$ a (much too large) ST-gap of $8.69 \mathrm{kcal} / \mathrm{mol}$ at infinite length was obtained from an extrapolation of CASCI/STO-3G data obtained for acenes ranging from benzene up to dodecacene, using a fitting function of the form $a+b \mathrm{e}^{-c}$. In their work, Hachmann et al. ${ }^{13}$ also proposed a value of $3.33 \mathrm{kcal} / \mathrm{mol}$ for the $\mathrm{ST}$-gap of an infinitely long chain of polyacene, based on an extrapolation of CASCI/cc-pVDZ data obtained for acenes ranging from naphthalene up to hexacene. Restricting the extrapolation of the CASCI/STO-3G data to the terms ranging from naphthalene to hexacene gives an intermediate ST-gap of $6.61 \mathrm{kcal} /$ mol in the polymer limit, which demonstrates that overlooking the importance of the basis set in treatments of correlation may yield errors as large, if not larger, than errors due to truncating the extrapolation range.

Exciton binding energies of $n$-acenes in periodic lattices are known to decrease faster than $n^{-1}$, according to band structure calculations ${ }^{82}$ of the dielectric tensor on the four first-terms $(n=2-5)$ of the series by solving the BetheSalpeter equation for the electron-hole Green's function. In the absence of localization effects into excitonic waves, adiabatic and vertical estimates for the ST gaps ought to converge to the same value in the polymer limit $(n \rightarrow \infty)$. Standard nonlinear least squares fitting of our final sets of $\mathrm{VE}_{\mathrm{S}-\mathrm{T}}$ and $\mathrm{AE}_{\mathrm{S}-\mathrm{T}}$ data in Table XVI by means of the above fitting function gives estimates of $0.27 \mathrm{kcal} / \mathrm{mol}$ (Ref. 83) and $-0.37 \mathrm{kcal} / \mathrm{mol}$ (Ref. 84) for the vertical and adiabatic STgaps of $n$-acenes in the polymer limit $(n \rightarrow \infty)$. Residual differences from these fits do not exceed 0.8 and $0.6 \mathrm{kcal} / \mathrm{mol}$, respectively. Estimates of 3.75 (Ref. 85 ) and $-0.22 \mathrm{kcal} / \mathrm{mol}$ (Ref. 86) are correspondingly obtained if benzene is excluded from the fit. A further estimate of $3.50 \mathrm{kcal} / \mathrm{mol}$ is obtained in the polymer limit for the vertical ST-gap when using in the $\mathrm{fit}^{87}$ the symmetry-broken FPA_5Z2 value of $104.37 \mathrm{kcal} / \mathrm{mol}$ (Table XIV) for the $\mathrm{VE}_{\mathrm{S}-\mathrm{T}}$ gap of benzene. In view of the dependence of the extrapolated results upon details of the fit, it can only be tentatively concluded that in this limit, the lowest singlet and triplet states should be degenerate within $\sim 4 \mathrm{kcal} / \mathrm{mol}(\sim 0.17 \mathrm{eV})$, which qualita- tively corroborates the absence of Peierls distortions in this limit, ${ }^{14}$ and the closure of the fundamental gap therefore (see Fig. 2 in Ref. 9).

Indeed, at the RB3LYP/cc-pVTZ level, "outer" bond lengths around the central ring of heptacene do not differ by more than $0.008 \AA$. Alternations between these bond lengths monotonically decrease with increasing system size (Fig. 5) and vanish in the polymer limit. ${ }^{15}$ In line with these geometrical features, structure factors computed for spin-spin and charge-charge correlation functions on the ground of density matrix renormalization group calculations using an empirical Pariser-Parr-Pople Hamiltonian also demonstrate that infinite polyacenes in their electronic ground state favor uniform charge distribution with no oscillations in spin densities or charge densities. ${ }^{9}$

\section{CONCLUSIONS}

The physical nature of the singlet electronic ground state of benzene and $n$-acenes ranging from naphthalene to heptacene has been thoroughly discussed, on the ground of singleand multireference calculations based on restricted or unrestricted zero-order wave functions. High-level and large scale treatments of electronic correlation in the singlet ground state are found to be necessary for compensating giant but unphysical symmetry-breaking effects in unrestricted single-reference treatments. The composition of multiconfigurational wave functions, the topologies of natural orbitals in symmetry-unrestricted CASSCF calculations, the T1 diagnostics of coupled cluster theory, and further energy-based criteria (\% TAE $(\mathrm{HF})$ and \% TAE $[(\mathrm{T})])$ demonstrate that all investigated systems exhibit a ${ }^{1} A_{g}$ singlet closed-shell electronic ground state.

A most common misconception among quantum chemists is to believe that releasing symmetry restrictions over space or spin in order to minimize the energy of a single Slater determinant, according to the variation theorem, necessarily yields the most suitable zero-order wave function for a post-SCF treatment of electron correlation, whereas RHF solutions ought to be proscribed. A most classical argument in favor of unrestricted approaches is the failure of restricted HF or DFT theories in describing bond dissociations. It is for instance well known that a RHF treatment of $\mathrm{H}_{2}$ using a minimal basis set of two $1 \mathrm{~s}$ atomic functions centered at the nuclei leads to an overestimation of the energy by $243 \mathrm{kcal} /$ mol at infinite nuclear separation. However, even in this case, the correct energy, amounting to twice that of the isolated hydrogen atom, is recovered by adding to the RHF energy the full-CI (in this particular case, SDCI) estimate in that minimal basis set for the correlation energy (see Eq. 4.24 in Ref. 51 and discussion therein).

The present contribution convincingly demonstrates that a UHF wave function is not necessarily a better starting point than a RHF wave function for dealing with (symmetryrestoring) dynamical correlation in symmetry-breaking situations. On the contrary, in such situations, the variational energy minimum form of the unrestricted $\mathrm{HF}$ wave function may represent one of the worst choices for a post-SCF treatment of electron correlation (see Ref. 29, see also Ref. 88 for 
a general discussion of the CI energy dependence of oneparticle orbital bases obtained as SCF solutions of a generalized Fock operator incorporating two independent parameters for scaling the Coulomb and exchange potential). From Eqs. (10) and (16) in Ref. 29, it is clear that the extent of symmetry-breaking complications in unrestricted treatments will smoothly increase with increasing system size, and decreasing band gap thereby, to reach asymptotically its climax at the polymer limit, where the band gap and the lowest excitation energies are expected to vanish in the absence of Peierls distorsions, ${ }^{9}$ a (metallic) scenario which the present contribution seems to confirm. Indeed, the T1 diagnostics and the energy-based \% TAE(HF) and \%TAE[(T)] criteria corroborate the idea that multireference effects very slowly increase with system size. However, for all selected systems, the values of these diagnostics indicate that there is no risk at all in assuming a single-reference depiction.

Since a single-reference depiction prevails for the electronic ground state, the vertical singlet-triplet excitation energies of benzene and $n$-acenes ranging from naphthalene to heptacene have been quantitatively determined from an extrapolation of the results of single-reference many-body calculations to the confines of nonrelativistic quantum mechanics for solving the electronic Schrödinger equation in clamped-nuclei configurations. The present study is based on various FPAs that exploit the overall smooth and regular convergence of electronic energy differences with regard to the size of the basis set and level of correlation attained in calculations employing the HF, MP2, MP3, MP4SDQ, CCSD, and $\operatorname{CCSD}(\mathrm{T})$ approaches along with increasingly complete Dunning's correlation consistent polarized valence basis sets (up to 2190 basis functions for heptacene). Such analyses allow us to perform extrapolations to the $\operatorname{CCSD}(\mathrm{T})$ level in conjunction with asymptotically CBSs. At the so called FPA_5Z2 level [Eq. (6)], which amounts specifically to an extrapolation to the $\operatorname{CCSD}(\mathrm{T}) / \mathrm{cc}-\mathrm{pV} \infty \mathrm{Z}$ level, based on three-point Feller's and Schwartz's extrapolations of HF results and MP2 correlation energies obtained using Dunning's cc-pVXZ basis sets $(X=\{T, Q, 5\})$, in combination with +MP3/cc-pvQZ, +MP4SDQ/cc-pVQZ, +CCSD/cc-pVQZ, and $+\operatorname{CCSD}(\mathrm{T}) / \mathrm{cc}-\mathrm{pVQZ}$ corrections, benzene, naphthalene, anthracene, naphthacene, pentacene, hexacene, and heptacene are found to have vertical singlet-triplet energy gaps of $100.79,76.28,56.97,40.69,31.51,22.96$, and $18.16 \mathrm{kcal} /$ mol, respectively. Upon accounting for zero-point vibrational energies and geometry relaxation effects, the adiabatic singlet-triplet energy gaps of these compounds are correspondingly estimated to be around 87.02, 62.87, 46.22, $32.23,24.19,16.79$, and $12.56 \mathrm{kcal} / \mathrm{mol}$. The estimated adiabatic values are in excellent match with the available experimental values, taking into account the likely influence of the environment in solid matrices or solvents. The largest deviations between the results obtained using our various extrapolation schemes (FPA_QZ, FPA_AQZ, FPA_5Z, and FPA_5Z2) for the vertical [or well-to-well] ST-gaps of benzene and of $n$-acenes $(n=2,3,4,5,6,7)$ do not exceed 0.70 [0.64], 0.45 [0.55], 0.36 [0.49], 0.28 [0.44], 0.33 [0.42], 0.37 [0.39], and $0.40[0.38] \mathrm{kcal} / \mathrm{mol}$, respectively. This observa- tion along with our analysis of multireference effects makes us believe that, regardless of possible complications pertaining to nuclear motions, we managed to grasp the lowest excitation energies of acenes up to heptacene in vacuum within chemical accuracy $(1 \mathrm{kcal} / \mathrm{mol}$, i.e., $43.4 \mathrm{meV})$. Further extrapolations with respect to system size indicate within an accuracy of a few $\mathrm{kcal} / \mathrm{mol}$ only that both the lowest vertical and adiabatic ST excitation energies tend to vanish in the polymer limit $(n \rightarrow \infty)$. Because of larger uncertainties on energy differences, it is at this stage still not possible to unambiguously determine whether the electronic ground state of finite acenes approaching the polymer limit would possess a singlet, a triplet, or even a higher spin-multiplet function.

The accuracy obtainable via extrapolations toward the CBS limit is very much dependent on the rate of convergence of the correlation energy in the orbital expansion, which can be frustratingly protracted in large conjugated systems. One of the most promising developments in response to the sluggish convergence rates of the one-particle expansion found in traditional correlation treatments has been the emergence of linear R12 methods. ${ }^{89}$ These techniques explicitly include the interelectronic distance, R12, in the functional form of the wave function, resulting in a wave function that exhibits the proper behavior with respect to electron cusp conditions and a more rapid convergence thereby of the correlation energy to the CBS limit. It would therefore be useful to evaluate the outcome of explicitly correlated R12 wave functions in further studies of the electronic properties of large conjugated compounds employing the principles of a FPA. In view of the scarcity of accurate experimental determinations of the excitation properties of large conjugated systems, a main general conclusion of our work is that, nowadays, many-body quantum chemical calculations can deliver transition energies at very high accuracies, sometimes competing with experiment. As was clearly shown in this paper, this no longer true only for atoms and small molecules of academic interest, but also for large conjugated compounds that are currently attracting much attention in the field of materials sciences and molecular engineering.

\section{ACKNOWLEDGMENTS}

Geometry optimizations, RRHO analyses, and all manybody [MP2, MP3, MP4SDQ, CCSD, and CCSD(T)] calculations presented in this work have been performed on Compaq (HP) ES45 and ES47 workstations at Hasselt University, Belgium, and at the Flemish Supercomputer Center (Vlaams Supercomputer Centrum). CASSCF and CASPT2 calculations were run at the VUB/ULB computer center (Hydra) and on PC clusters of the Inorganic and Analytical Chemistry Department at the University of Technology and Economics in Budapest (Osiris). This work has been supported by the FWO-Vlaanderen, the Flemish branch of the Belgian National Science Foundation, and by the Bijzonder OnderzoeksFonds of Hasselt University. B.H. gratefully acknowledges financial support from the scientific research network "Density Functional Theory: Fundamental and Applied Aspects" sponsored by the FWO-Vlaanderen (Belgium). P.G., 
F.D.P., and M.S.D. wish to acknowledge their universities (Vrije Universiteit Brussel, Universiteit Hasselt) and the Fund for Scientific Research-Flanders (Belgium) (FWO) for continuous support to their research groups. B.H., F.D.P., and M.S.D. especially acknowledge financial support from two Research Programs of the Research Foundation-Flanders (FWO) (Project Nos. G.0464.06 and G.0350.09N). B.H. and M.S.D. are grateful to Professor L. S. Cederbaum (Universität Heidelberg, Germany) for useful discussions on the nonanalyticity of SCF procedures and symmetry breakings.

${ }^{1}$ E. Clar, Polycyclic Hydrocarbons (Academic, London, 1964); R. G. Havey, Polycyclic Aromatic Hydrocarbons (Wiley-VCH, New York, 1997).

${ }^{2}$ G. C. Smith and J. F. Sinski, Appl. Spectrosc. 53, 1459 (1999).

${ }^{3}$ J. Jacob, Pure Appl. Chem. 68, 301 (1996).

${ }^{4}$ J. L. Weisman, T. J. Lee, F. Salama, and M. Head-Gordon, Astrophys. J. 587, 256 (2003).

${ }^{5}$ X. Chillier, P. Boulet, H. Chermette, F. Salama, and J. Weber, J. Phys. Chem. 115, 1769 (2001); F. Salama, J. Mol. Struct. 563-564, 19 (2001); P. Brèchignac and T. Pino, Astron. Astrophys. 343, L49 (1999).

${ }^{6}$ A. Shimizu and H. Tachikawa, Electrochim. Acta 48, 1727 (2003).

${ }^{7}$ M. S. Deleuze, J. Am. Chem. Soc. 122, 1130 (2000); Y. Okamoto and Y Miyamoto, J. Phys. Chem. B 105, 3470 (2001); T. J. Frankcombe, S. K. Bhatia, and S. C. Smith, Carbon 40, 2341 (2002); B. Hajgató, M. S. Deleuze, and K. Ohno, Chemistry (Weinheim, Ger.) 12, 5757 (2006); P. Bultinck, Faraday Discuss. 135, 347 (2007); J. S. Wu, W. Pisula, and K. Mullen, Chem. Rev. (Washington, D.C.) 107, 718 (2007); N. Park, S. Hong, G. Kim, and S.-H. Jhi, J. Am. Chem. Soc. 129, 8999 (2007); M. Koshino and T. Ando, Solid State Commun. 149, 1123 (2009); H. Tachikawa, Y. Nagoya, and H. Kawabata, J. Chem. Theory Comput. 5, 2101 (2009); E. Yurtsever, J. Phys. Chem. A 113, 924 (2009).

${ }^{8}$ H. C. Longuet-Higgins and L. Salem, Proc. R. Soc. London, Ser. A 255 , 5435 (1960); M. Kertesz and R. Hoffmann, Solid State Commun. 47, 97 (1983); S. Kivelson and O. L. Chapman, Phys. Rev. B 28, 7236 (1983). ${ }^{9}$ C. Raghu, Y. A. Pati, and S. Ramaseha, Phys. Rev. B 65, 155204 (2002).

${ }^{10}$ C. D. Dimitrakopoulos, S. Purishotoman, J. Kymissis, A. Callegari, and M. J. Shaw, Science 283, 822 (1999); C. D. Dimitrakopoulos and P. R. L. Malenfant, Adv. Mater. (Weinheim, Ger.) 14, 99 (2002); S. Verlaak, S. Steudel, P. Heremans, D. Janssen, and M. S. Deleuze, Phys. Rev. B 68 , 195409 (2003); T. W. Kelley, D. V. Muyres, P. F. Baude, T. P. Smith, T. D. Jones, Mater. Res. Soc. Symp. Proc. 771, L6.5.1 (2003); C. D. Sheraw, T. N. Jackson, D. L. Eaton, and J. E. Anthony, Adv. Mater. (Weinheim, Ger.) 15, 2009 (2003); R. Ruiz, D. Choudhary, B. Nickel, T. Toccoli, K.-C. Chang, A. C. Mayer, P. Clancy, J. M. Blakely, R. L. Headrick, S. Iannotta, and G. G. Malliaras, Chem. Mater. 16, 4497 (2004); C. Reese, M. Roberts, M. Ling, and Z. Bao, Mater. Today 7, 20 (2004); V. C. Sundar, J. Zaumseil, V. Podzorov, E. Menard, R. L. Willett, T. Someya, M. E. Gershenson, and J. A. Rogers, Science 303, 1644 (2004); M. M. Payne, S. R. Parkin, J. E. Anthony, C.-C. Kuo, and T. N. Jackson, J. Am. Chem. Soc. 127, 4986 (2005); H. S. Lee, D. H. Kim, J. H. Cho, Y. D. Park, J. S. Kim, and K. Cho, Adv. Funct. Mater. 16, 1859 (2006); F. Würthner and R. Schmidt, ChemPhysChem 7, 793 (2006); J. E. Anthony, Angew. Chem., Int. Ed. 47, 452 (2008); J. A. Lim, H. S. Lee, W. H. Lee, and K. Cho, Adv. Funct. Mater. 19, 1515 (2009).

${ }^{11}$ See e.g. H. Angliker, E. Rommel, and J. Wirz, Chem. Phys. Lett. 87, 208 (1982); K. N. Houk, P. S. Lee, and M. Nendel, J. Org. Chem. 66, 5517 (2001); D. R. McMasters and J. Wirz, J. Am. Chem. Soc. 123, 238 (2001); L. P. Huang, D. Rocca, S. Baroni, K. E. Gubbins, and M. D. Nardelli, J. Chem. Phys. 130, 194701 (2009).

${ }^{12}$ M. Bendikov, H. M. Duong, K. Starkey, K. N. Houk, E. A. Carter, and F. Wudl, J. Am. Chem. Soc. 126, 7416 (2004); 126, 10493(E) (2004).

${ }^{13}$ J. Hachmann, J. J. Dorando, M. Avilés, and G. K.-L. Chan, J. Chem. Phys. 127, 134309 (2007).

${ }^{14}$ Z. Qu, D. Zhang, C. Liu, and Y. Jiang, J. Phys. Chem. A 113, 7909 (2009).

${ }^{15}$ M. C. dos Santos, Phys. Rev. B 74, 045426 (2006); D.-e. Jiang and S. Dai, J. Phys. Chem. A 112, 332 (2008).

${ }^{16}$ T. Ishida and J. Aihara, Phys. Chem. Chem. Phys. 11, 7197 (2009).

${ }^{17}$ M. S. Deleuze, L. Claes, E. S. Kryachko, and J.-P. François, J. Chem. Phys. 119, 3106 (2003).

${ }^{18}$ B. Hajgató, M. S. Deleuze, D. J. Tozer, and F. De Proft, J. Chem. Phys.
129, 084308 (2008).

${ }^{19}$ N. L. Allinger, J. T. Ferman, W. D. Allen, and H. F. Schaefer III, J. Chem. Phys. 106, 5143 (1997); A. G. Császár, W. D. Allen, and H. F. Schaefer III, “ ibid." 108, 9751 (1998); A. Salam and M. S. Deleuze, J. Chem. Phys. 116, 1296 (2002); E. Czinki and A. G. Császár, Chemistry (Weinheim, Ger.) 9, 1008 (2003); S. P. Kwasniewski, L. Claes, J.-P. François, and M. S. Deleuze, J. Chem. Phys. 118, 7823 (2003); K. Kahn and T. C. Bruice, Theor. Chem. Acc. 111, 18 (2004); A. G. Császár, V. Szalay, and M. L. Senent, J. Chem. Phys. 120, 1203 (2004); K. Kahn and T. C. Bruice, ChemPhysChem 6, 487 (2005); K. Kahn and I. Kahn, J. Comput. Chem. 29, 900 (2008); J. Demaison, J. Liévin, A. G. Császár, and C. Guttle, J. Phys. Chem. A 112, 4477 (2008); O. S. Bokareva and V. A. Bataev, Int. J. Quantum Chem. 108, 2719 (2008); T. Szidarovszky, G. Czakó, and A. G. Császár, Mol. Phys. 107, 761 (2009); J. J. Wilke, M. C. Lind, H. F. Schaefer III, A. G. Császár, and A. D. Allen, J. Chem. Theory Comput. 5, 1511 (2009); R. M. Balabin, Chem. Phys. Lett. 479, 195 (2009); E. V. Rastoltseva, V. A. Bataev, and I. A. Godunov, J. Mol. Struct.: THEOCHEM 905, 86 (2009).

${ }^{20}$ G. Tarczay, A. G. Császár, W. Klopper, and V. Szalay, J. Chem. Phys. 110, 11971 (1999).

${ }^{21}$ S. J. Klippenstein, A. L. L. East, and W. D. Allen, J. Chem. Phys. 105, 118 (1996); E. F. Valeev, W. D. Allen, H. F. Schaefer III, A. G. Császár, and A. L. L. East, J. Phys. Chem. A 105, 2716 (2001); N. D. Petraco, W. D. Allen, and H. F. Schaefer III, J. Chem. Phys. 116, 10229 (2002); S. E. Wheeler, W. D. Allen, and H. F. Schaefer III, ibid. 121, 8800 (2004).

${ }^{22}$ K.-C. Lau and C. Y. Ng, J. Chem. Phys. 122, 224310 (2005).

${ }^{23}$ A. L. L. East and W. D. Allen, J. Chem. Phys. 99, 4638 (1993); A. G. Császár, M. L. Leininger, and V. Szalay, ibid. 118, 10631 (2003); M. S. Schuurman, S. R. Muir, W. D. Allen, and H. F. Schaefer III, ibid. 120, 11586 (2004).

${ }^{24}$ J. C. Sancho-García, Chem. Phys. Lett. 468, 138 (2009).

${ }^{25}$ M. S. Deleuze, A. B. Trofimov, and L. S. Cederbaum, J. Chem. Phys. 115, 5859 (2001); M. S. Deleuze, ibid. 116, 7012 (2002); M. S. Deleuze, J. Phys. Chem. A 108, 9244 (2004); M. S. Deleuze, Chem. Phys. 329, 22 (2006); S. Knippenberg and M. S. Deleuze, J. Electron Spectrosc. Relat. Phenom. (in press, corrected proof available online) DOI:10.1016/ j.elspec.2009.04.013.

${ }^{26}$ D. Moran, A. C. Simmonett, F. E. Leach III, W. D. Allen, P. R. Schleyer, and H. F. Schaefer III, J. Am. Chem. Soc. 128, 9342 (2006).

${ }^{27}$ E. R. Davidson and W. T. Borden, J. Phys. Chem. 87, 4783 (1983).

${ }^{28}$ F. Jensen, Introduction to Computational Chemistry (Wiley, Chichester, 1999); C. J. Cramer, Essentials of Computational Chemistry, 2nd ed. (Wiley, Chichester, 2004).

${ }^{29}$ L. S. Cederbaum, F. Tarantelli, and P. Winkler, J. Phys. B 23, L747 (1990); L. S. Cederbaum and P. Winkler, Theor. Chim. Acta 88, 257 (1994).

${ }^{30}$ The correct symmetries are dictated by the full Hamiltonian. In the absence of spin orbit coupling, the eigenstates of this Hamiltonian are pure spin states (singlet, triplet, etc.), and the exact wave functions must transform like irreducible representations of the molecular point group. Consequently, if an unrestricted SCF procedure enforces different localizations for the $\alpha$ and $\beta$ orbitals in a singlet open-shell wave function, a spin-contamination by triplet, quintet, etc., states arises $\left(\left\langle S^{2}\right\rangle>0\right)$, and the result of the SCF calculation is trivially "unphysical," due to an incomplete (e.g. UHF) or too approximate (e.g. UB3LYP, UBLYP, etc.) treatment of electron correlation.

${ }^{31}$ In spite of the fact that spin contamination is not well defined in DFT methods [see, e.g., J. A. Pople, P. M. W. Gill, and N. C. Handy, Int. J. Quantum Chem. 56, 303 (1995)], charge and spin densities should exhibit the full symmetry of the molecular point group; J. P. Perdew, A. Ruzinsky, L. A. Constantin, J. Sin, and G. I. Csonka, ibid. 5, 902 (2009).

${ }^{32}$ A. P. Monkman, H. D. Burrows, L. J. Hartwell, L. E. Horsburgh, I. Hamblett, and S. Navaratnam, Phys. Rev. Lett. 86, 1358 (2001).

${ }^{33}$ W. Siebrand, J. Chem. Phys. 47, 2411 (1967) (and references therein).

${ }^{34}$ J. B. Birks, Photophysics of Aromatic Molecules (Wiley, London, 1970); J. B. Birks, Organic Molecular Photophysics (Wiley, London, 1975), Vol. 2.

${ }^{35}$ J. Schiedt and R. Weinhauf, Chem. Phys. Lett. 266, 201 (1997).

${ }^{36}$ R. Mondal, R. M. Adhikari, B. K. Shah, and D. C. Neckers, Org. Lett. 9, 2505 (2007)

${ }^{37}$ R. Mondal, B. K. Shah, and D. C. Neckers, J. Am. Chem. Soc. 128, 9612 (2006).

${ }^{38}$ Y. Kawashima, T. Hashimoto, H. Nakano, and K. Hirao, Theor. Chem. Acc. 102, 49 (1999). 
${ }^{39}$ C. Raghu, A. Pati, and S. Ramaseha, Phys. Rev. B 66, 035116 (2002).

${ }^{40}$ S. Grimme and M. Parac, ChemPhysChem 4, 292 (2003); E. S. Kadantsev, M. J. Stott, and A. Rubio, J. Chem. Phys. 124, 134901 (2006).

${ }^{41}$ R. Dreizler and E. Gross, Density Functional Theory (Plenum, New York, 1995).

${ }^{42}$ C. Lee, W. Yang, and R. G. Parr, Phys. Rev. B 37, 785 (1988); A. D. Becke, J. Chem. Phys. 98, 5648 (1993).

${ }^{43}$ T. H. Dunning, Jr., J. Chem. Phys. 90, 1007 (1989).

${ }^{44}$ J. M. L. Martin, J. El-Yazal, and J.-P. François, Mol. Phys. 86, 1437 (1995); M. S. Deleuze, M. G. Giuffreda, and J.-P. François, J. Phys. Chem. A 106, 5626 (2002).

${ }^{45}$ G. D. Purvis and R. J. Bartlett, J. Chem. Phys. 76, 1910 (1982); G. E. Scuseria, C. L. Janssen, and H. F. Schaefer III, ibid. 89, 7382 (1988); K. Raghavachari, G. W. Trucks, M. Head-Gordon, and J. A. Pople, Chem. Phys. Lett. 157, 479 (1989); R. J. Bartlett, J. Phys. Chem. 93, 1697 (1989)

${ }^{46}$ J. M. L. Martin and G. de Oliveira, J. Chem. Phys. 111, 1843 (1999); S. Parthiban and J. M. L. Martin, ibid. 114, 6014 (2001).

${ }^{47}$ T. Helgaker, P. Jørgensen, and J. Olsen, Molecular Electronic-Structure Theory (Wiley, Chichester, 2000).

${ }^{48}$ K. Andersson, P.-Å. Malmqvist, B. O. Roos, A. J. Sadlej, and K. Wolinski, J. Phys. Chem. 94, 5483 (1990); K. Andersson, P.-Å. Malmqvist, and B. O. Roos, J. Chem. Phys. 96, 1218 (1992).

${ }^{49}$ K. Andersson, Theor. Chim. Acta 91, 31 (1995).

${ }^{50}$ K. Andersson and B. O. Roos, Int. J. Quantum Chem. 45, 591 (1993).

${ }^{51}$ A. Szabo and N. S. Ostlund, Modern Quantum Chemistry (McGraw-Hill, New York, 1982).

${ }^{52}$ C. Møller and M. S. Plesset, Phys. Rev. 46, 618 (1934).

${ }^{53}$ M. Head-Gordon, J. A. Pople, and M. J. Frisch, Chem. Phys. Lett. 153, 503 (1988).

${ }^{54}$ J. A. Pople, R. Seeger, and R. Krishnan, Int. J. Quant. Chem. Symp. 11, 149 (1977).

${ }^{55}$ R. Krishnan and J. A. Pople, Int. J. Quantum Chem. 14, 91 (1978).

${ }^{56}$ K. A. Peterson, E. E. Woon, and T. H. Dunning, Jr., J. Chem. Phys. 100 7410 (1994).

${ }^{57}$ R. A. Kendall, T. H. Dunning, Jr., and R. J. Harrison, J. Chem. Phys. 96, 6796 (1992).

${ }^{58}$ P. G. Szalay and R. J. Bartlett, Chem. Phys. Lett. 214, 481 (1993).

${ }^{59}$ M. J. Frisch, G. W. Trucks, H. B. Schlegel, et al., GAUSSIAN 03, Revision D.01, Gaussian, Inc., Wallingford CT, 2004.

${ }^{60}$ MOLPRO, a package of ab initio programs written by H.-J. Werner and P. J. Knowles, with contributions from R. D. Amos, A. Bernhardsson, A. Berning, et al.; For integral evaluation see R. Lindh, U. Ryu, and B. Liu, J. Chem. Phys. 95, 5889 (1991); For partially spin restricted open-shell coupled cluster see P. J. Knowles, C. Hampel, and H.-J. Werner, ibid. 99, 5219 (1993); 112, 3106(E) (2000); For perturbative triples see J. D. Watts, J. Gauss, and R. J. Bartlett, ibid. 98, 8718 (1993).

${ }^{61}$ Molcas, Version 5.4, K. Andersson, M. Barysz, A. Bernhardsson, M. R. A. Blomberg, Y. Carissan, D. L. Cooper, M. P. Fülscher, L. Gagliardi, C. de Graaf, B. A. Hess, G. Karlström, R. Lindh, P.-Å. Malmqvist, T. Nakajima, P. Neogrády, J. Olsen, B. O. Roos, B. Schimmelpfennig, M. Schütz, L. Seijo, L. Serrano-Andrés, P. E. M. Siegbahn, J. Stålring, T. Thorsteinsson, V. Veryazov, and P.-O. Widmark, Lund University, Sweden, 2002.

${ }^{62}$ J. F. Stanton, J. Gauss, J. D. Watts, P. G. Szalay, and R. J. Bartlett with contributions from A. A. Auer, D. E. Bernholdt, O. Christiansen, M. E Harding, M. Heckert, O. Heun, C. Huber, D. Jonsson, J. Jusélius, W. J. Lauderdale, T. Metzroth, C. Michauk, D. R. Price, K. Ruud, F. Schiffmann, A. Tajti, M. E. Varner, and J. Vázquez, http://www.aces2.de; J. F. Stanton, J. Gauss, J. D. Watts, W. J. Lauderdale, and R. J. Bartlett, Int. J. Quantum Chem. Symp. 26, 897 (1992).

${ }^{63}$ MRCC, a string-based quantum chemical program suite written by M. Kállay, http://www.mrcc.hu/; M. Kállay and P. R. Surján, J. Chem. Phys. 115, 2945 (2001)

${ }^{64}$ O. Christiansen, H. Koch, and P. Jørgensen, Chem. Phys. Lett. 243, 409 (1995).

${ }^{65}$ H. Koch, O. Christiansen, P. Jørgensen, A. M. Sanchez de Meras, and T. Helgaker, J. Chem. Phys. 106, 1808 (1997).
${ }^{66}$ M. Kállay and J. Gauss, J. Chem. Phys. 123, 214105 (2005).

${ }^{67}$ J. Noga and R. J. Bartlett, J. Chem. Phys. 86, 7041 (1987); 89, 3401(E) (1988); G. E. Scuseria and H. F. Schaefer III, Chem. Phys. Lett. 152, 382 (1988).

${ }^{68}$ Y. Bomble, M. Kállay, J. Gauss, and J. F. Stanton, J. Chem. Phys. 123, 054101 (2005).

${ }^{69}$ N. Oliphant and L. Adamowicz, J. Chem. Phys. 95, 6645 (1991); S. A. Kucharski and R. J. Bartlett, ibid. 97, 4282 (1992).

${ }^{70}$ D. Feller, J. Chem. Phys. 96, 6104 (1992); 98, 7059 (1993).

${ }^{71}$ J. M. L. Martin, in Energetics of Stable Molecules and Reactive Intermediates, NATO ASI Symposium Series, edited by M. E. Mirrasda Piedade and K. K. Irikura (Kluwer, Dordrecht, 1999).

${ }^{72}$ C. Schwartz, in Methods in Computational Physics, edited by B. J. Alder (Academic, New York, 1963), Vol. 2.

${ }^{73}$ N. X. Wang and A. K. Wilson, J. Chem. Phys. 121, 7632 (2004).

${ }^{74}$ K. Aa. Christensen and F. Jensen, Chem. Phys. Lett. 317, 400 (2000).

${ }^{75}$ T. J. Lee and P. R. Taylor, Int. J. Quantum Chem., Quantum Chem. Symp. 23, 199 (1989).

${ }^{76}$ A. Karton, E. Rabinovitch, J. M. L. Martin, and B. Ruscic, J. Chem. Phys. 125, 144108 (2006).

${ }^{77}$ A. Karton, J. M. L. Martin, and P. R. Taylor, J. Chem. Phys. 127, 064104 (2007).

${ }^{78}$ A. D. Boese, M. Oren, O. Atasoyulu, J. M. L. Martin, M. Kállay, and J. Gauss, J. Chem. Phys. 120, 4129 (2004); A. Tajti, P. G. Szalay, A. G. Császár, M. Kállay, J. Gauss, E. F. Valeev, B. A. Flowers, J. Vázquez, and J. F. Stanton, ibid. 121, 11599 (2004); T. A. Ruden, T. Helgaker, P. Jørgensen, and J. Olsen, Chem. Phys. Lett. 371, 62 (2003); J. Chem. Phys. 121, 5874 (2004); D. Feller, K. A. Peterson, and T. D. Crawford, ibid. 124, 054107 (2006).

${ }^{79}$ A. Karton, B. Ruscic, and J. M. L. Martin, J. Mol. Struct.: THEOCHEM 811, 345 (2007).

${ }^{80}$ F. Márquez, C. M. Zicovich-Wilson, A. Corma, E. Palomares, and H. García, J. Phys. Chem. B 105, 9973 (2001).

${ }^{81}$ F. Márquez, H. García, E. Palomares, L. Fernandez, and A. Corma, J. Am. Chem. Soc. 122, 6520 (2000).

${ }^{82}$ K. Hummer and C. Ambrosch-Draxl, Phys. Rev. B 71, 081202 (2005).

${ }^{83} \mathrm{E}_{\mathrm{S}-\mathrm{T}}=0.26582+135.57 \mathrm{e}^{-0.29449 \text { Rings }}\left(\mathrm{R}^{2}=0.9993\right)$.

${ }^{84} \mathrm{E}_{\mathrm{S}-\mathrm{T}}=-0.37357+120.55 \mathrm{e}^{-0.32140 \text { Rings }}\left(\mathrm{R}^{2}=0.9997\right)$.

${ }^{85} \mathrm{E}_{\mathrm{S}-\mathrm{T}}=3.7534+140.03 \mathrm{e}^{-0.32736 \text { Rings }}\left(\mathrm{R}^{2}=0.9992\right)$.

${ }^{86} \mathrm{E}_{\mathrm{S}-\mathrm{T}}=-0.22259+120.78 \mathrm{e}^{-0.32317 \text { Rings }}\left(\mathrm{R}^{2}=0.9993\right)$.

${ }^{87} \mathrm{E}_{\mathrm{S}-\mathrm{T}}=3.4967+139.62 \mathrm{e}^{-0.32570 \text { Rings }}\left(\mathrm{R}^{2}=0.9993\right)$.

${ }^{88}$ F. Tarantelli and L. S. Cederbaum, J. Chem. Phys. 89, 4170 (1988).

${ }^{89}$ W. Klopper and W. Kutzelnigg, Chem. Phys. Lett. 134, 17 (1987); W. Kutzelnigg and W. Klopper, J. Chem. Phys. 94, 1985 (1991); J. Noga and W. Kutzelnigg, ibid. 101, 7738 (1994); W. Klopper and C. C. M. Samson, ibid. 116, 6397 (2002).

${ }^{90}$ B. J. Lynch, P. L. Fast, M. Harris, and D. G. Truhlar, J. Phys. Chem. A 104, 4811 (2000); B. J. Lynch and D. G. Truhlar, ibid. 105, 2936 (2001); L. Claes, J.-P. François, and M. S. Deleuze, J. Am. Chem. Soc. 124, 7563 (2002); 125, 7129 (2003).

${ }^{91}$ J. P. Perdew, in Electronic Structure of Solids '91, edited by P. Ziesche and H. Eschrig (Akademie, Berlin, 1991); J. P. Perdew, J. A. Chevary, S. H. Vosko, K. A. Jackson, M. R. Pederson, D. J. Singh, and C. Fiolhais, Phys. Rev. B 46, 6671 (1992); 48, 4978(E) (1993); J. P. Perdew, K. Burke, and Y. Wang, ibid. 54, 16533 (1996); K. Burke, J. P. Perdew, and Y. Wang, in Electronic Density Functional Theory: Recent Progress and New Directions, edited by J. F. Dobson, G. Vignale, and M. P. Das (Plenum, New York, 1998).

${ }^{92}$ A. D. Becke, Phys. Rev. A 38, 3098 (1988), and references in Ref. 91.

${ }^{93}$ J. M. Tao, J. P. Perdew, V. N. Staroverov, and G. E. Scuseria, Phys. Rev. Lett. 91, 146401 (2003).

${ }^{94}$ J. P. Perdew, K. Burke, and M. Ernzerhof, Phys. Rev. Lett. 77, 3865 (1996); 78, 1396(E) (1997).

${ }^{95}$ J. Burgos, M. Pope, Ch. E. Swenberg, and R. R. Alfano, Phys. Status Solidi B 83, 249 (1977).

${ }^{96}$ Contour plots were made using the MOLDEN program. G. Schaftenaar and J. H. Noordik, J. Comput. Aided Mol. Design 14, 123 (2000). 